\title{
The potential of QuikSCAT and WindSat observations for the estimation of sea surface wind vector under severe weather conditions
}

\author{
Y. Quilfen ${ }^{1, *}$, C. Prigent ${ }^{2}$, B. Chapron ${ }^{1}$, A. A. Mouche ${ }^{1}$, N. Houti ${ }^{2}$ \\ ${ }^{1}$ Laboratoire d'Océanographie Spatiale, IFREMER, Plouzané, France \\ ${ }^{2}$ Laboratoire d'Etude du Rayonnement et de la Matière en Astrophysique, Observatoire de Paris, Paris, France \\ *: Corresponding author : Quilfen Y., email address : $\underline{\text { Yves.Quilfen@ifremer.fr }}$
}

\begin{abstract}
:
The physics of remote sensing sea surface measurements is still poorly understood under severe weather conditions. Wind vector algorithms are usually developed for non-precipitating atmospheres and for wind speeds less than $20 \mathrm{~m} / \mathrm{s}$. In this study, we analyze observations from the QuikSCAT Kuband scatterometer collocated with the WindSat full polarimetric microwave radiometer to estimate the potential of these two instruments for sea surface wind retrieval under severe weather conditions. The Jason altimeter provides independent measurements of wind speed and rain rate for comparison purposes. The sensitivity of the radar cross-sections and brightness temperatures to the wind speed and direction is directly studied from the observations and compared with semi empirical models. This study clearly demonstrates that wind vector retrieval under extreme condition is feasible. Comparisons between QuikSCAT and WindSat coincident observations evidence a better sensitivity of the active mode to low and moderate winds and more sensitivity to high wind speeds in the passive mode. Although the WindSat observations are affected by water vapor, cloud, and rain, especially at and above $18 \mathrm{GHz}$, the measurements are sensitive to wind speed even at high wind speeds. Contrarily to the active instrument, there is no saturation at high winds. The sensitivity clearly tends to increase for winds above $15 \mathrm{~m} / \mathrm{s}$. For the wind direction, the amplitude of the azimuthal modulation in the active mode decreases with increasing wind speed, while it increases for the passive measurements. The development of specific wind retrievals under severe weather conditions is encouraged and a simple illustration is provided.
\end{abstract}

Keywords: Radiometer, scatterometer, winds. 


\section{1. Introduction}

48 No existing sensor has been specifically designed to probe the sea surface during

49 extreme weather events and there is a need to elaborate from existing sensors. Already

50 decided operational Earth observation missions for the coming 15 years include

51 scatterometers (the Meteorological Operational, MetOp, satellite series) and microwave

52 radiometers (the National Polar-Orbiting Operational Environmental Satellite System,

53 NPOESS, and MetOp satellite series). A critical review of the scatterometer and

54 microwave radiometer potentialities / limitations to measure the surface winds under

55 severe weather conditions is thus necessary. The sensitivity of the various instruments to

56 the extreme events has to be objectively analyzed, under the same conditions, i.e., when

57 coincident observations of both instruments are available. This can further lead to

58 potential synergies between active and passive measurements on future Earth observation

59 missions. The recent satellite polarimetric measurements from WindSat (Gaiser et al.,

60 2004), launched in January 2003 have not been completely explored yet and provide new

61 information under high wind speed and / or intense rain.

62 The physics of remote sensing measurements over sea surface is still poorly

63 understood under extreme conditions. Remote sensing at high wind speed is mostly

64 controlled by the observation ability to directly or indirectly probe the wave breaking

65 impacts. The wind vector algorithms are usually developed for non-precipitating

66 atmospheres and for wind speeds less than $20 \mathrm{~m} / \mathrm{s}$. Preliminary evaluations of the first

67 versions of the ocean wind algorithms from WindSat under hurricane conditions (Adams

68 et al., 2006) concluded that the wind speed was strongly affected by heavy clouds and

69 precipitation. However, these results were only obtained after less than 3 years of 
70 WindSat operation and full use of the polarimetric information combined to innovative 71 approaches should improve the retrievals (Adams et al., 2006). Concerning active 72 measurements, the larger wave breaking signatures as well as foam and bubble impacts 73 on the ocean surface dielectric and geometrical properties have been analyzed with 74 altimeter measurements (Quilfen et al., 2006). At larger incidence angles provided by 75 scatterometer observations, larger wave breakings can provide a very active source to 76 generate shorter scale roughness (Kudryavtsev and Johannessen, 2004) to help maintain 77 the wind speed sensitivity. Larger wave breaking events correspond to larger zones 78 covered with foam. More interestingly, larger breakers are associated with thicker foam 79 patches (Reul and Chapron, 2003). These two aspects (coverage and thickness) have 80 significant impacts on passive radiometric measurements.

81 In this study, we analyze multi-sensor observations from the QuikSCAT Ku-band 82 scatterometer collocated with the WindSat full polarimetric microwave radiometer. The 83 Jason altimeter mission provides independent measurements of wind speed, rain rate, and 84 atmospheric water content to help interpret the results. A systematic data screening tool 85 has been developed to collocate the three different sensors within a given space / time 86 window. The data are presented in section 2 , with special focus on the rain flagging 87 procedure. In section 3 , the sensitivity of the radar cross-section and brightness 88 temperatures to the wind speed and direction is studied from the observations and 89 compared with semi-empirical model simulations, with emphasis on the high wind speed 90 regime and on the effect of the atmospheric conditions. In section 4 , the nominal wind 91 vector retrievals from both WindSat and QuikSCAT are compared and presented to 92 highlight the possible residual errors in the WindSat wind vector retrieval. Finally, in 
93 section 5, retrievals using various observation combinations are tested, using both the

94 radiometer and the scatterometer, to help analyze the information content of passive and

95 active observations, and to show that the WindSat nominal wind speed retrieval can be

96 improved to provide valuable estimates as well as to complement the radar measurements

97 under severe weather conditions.

99 2. Data

\section{$100 \quad$ 2.1. The instrument characteristics}

\section{$101 \quad$ 2.1.1. WindSat}

102 Coriolis is a 3-year demonstration / validation mission sponsored by the Department of

103 Defense Space Test Program, the U.S. Navy, and the National Polar-Orbiting Operational

104 Environmental Satellite System (NPOESS) Integrated Program Office. It was launched

105 on January 6,2003 , on a geosynchronous polar orbit, with ascending node at 17:59 UTC.

106 WindSat onboard the Coriolis mission is a polarimetric microwave radiometer developed

107 and built by the Naval Research Laboratory (NRL). Its objective is to demonstrate the

108 potential of polarimetric measurements to estimate the ocean surface wind vector (speed

109 and direction).

110 The measurement principle makes use of the natural microwave emission of the sea

111 surface that varies with sea surface roughness. The rougher the sea, the more intense is

112 the emission. The received energy is a combination of energy emitted from the ocean

113 surface, from the atmosphere, and from the atmosphere reflected off the surface. WindSat

114 is the first space borne polarimetric microwave radiometer. It measures not only the

115 orthogonal polarizations (vertical and horizontal), but also the cross-correlation of the 
116 vertical and horizontal polarizations. The cross-correlation terms represent the third and

117 fourth parameters of the modified Stokes vector (U and F). The Stokes vector provides a

118 full characterization of the electromagnetic signature of the ocean surface, and the

119 independent information needed to determine the wind direction.

120 WindSat uses a 1.8-m offset reflector antenna fed by eleven dual-polarized feed horns.

121 It operates at $6.8,10.7,18.7,23.8$, and $37 \mathrm{GHz}$, with $10.7,18.7$, and $37 \mathrm{GHz}$ fully

122 polarimetric (the four Stokes parameters are measured, V, H, U, and F) whereas the other

123 channels are only measured in the two orthogonal polarizations ( $\mathrm{V}$ and $\mathrm{H}$ ). The Earth

124 incidence angle is close to $53^{\circ}$ (respectively $53.5^{\circ}, 49.9^{\circ}, 55.3^{\circ}, 53.0^{\circ}$ and $53.0^{\circ}$ for each

125 frequency) and the spatial resolution ranges from $40 \mathrm{~km} \mathrm{x} 60 \mathrm{~km}$ at $6.8 \mathrm{GHz}$ to $8 \mathrm{~km} \mathrm{x} 13$

$126 \mathrm{~km}$ at $37.0 \mathrm{GHz}$. The expected accuracy is $0.75 \mathrm{~K}$ for the $\mathrm{V}$ and $\mathrm{H}$ channels and $0.25 \mathrm{~K}$

127 for the third and fourth Stokes parameters. A complete description of the instrument and

128 its characteristics is given in Gaiser et al. (2004).

\section{$130 \quad$ 2.1.2. QuikSCAT}

131 The SeaWinds instrument on QuikSCAT is an active microwave radar designed to 132 measure the electromagnetic backscatter from the wind roughened ocean surface. The 133 SeaWinds instrument uses a rotating dish antenna with two spot beams that conically 134 sweep, producing a circular pattern on the surface. The antenna radiates microwave 135 pulses at a frequency of $13.4 \mathrm{GHz}$. The antenna spins at a rate of $18 \mathrm{rpm}$, scanning two 136 pencil-beam footprint paths at incidence angles of $46^{\circ}(\mathrm{H}-\mathrm{pol})$ and $54^{\circ}$ (V-pol). The 137 instrument collects data over ocean, land, and ice in a continuous, $1,800 \mathrm{~km}$ wide band 138 centred on the spacecraft nadir ground track, covering $90 \%$ of Earth's surface each day. 
139 Spaceborne scatterometers transmit microwave pulses to the ocean surface and

140 measure the backscattered power received at the instrument. Since atmospheric motions

141 themselves do not substantially affect the radiation emitted and received by the radar,

142 scatterometers use an indirect technique to measure wind velocity over the ocean. Wind

143 over the ocean generates ripples and small waves, which roughen the sea surface. These

144 waves modify the radar cross-section $\left(\sigma_{\mathrm{o}}\right)$ of the ocean surface and hence the magnitude

145 of backscattered power. In order to extract wind velocity from these measurements, a

146 relationship between $\sigma_{\mathrm{o}}$ and near-surface winds, known as the geophysical model

147 function, has to be established.

$148 \quad$ 2.2. The collocation methodology and criteria

149 The "Centre ERS d'Archivage et de Traitement" (CERSAT) located at the "Institut 150 Français de Recherche pour l'Exploitation de la Mer" (IFREMER, France) is a mirror site

151 for the QuikSCAT data and thus manages the archive of levels $2 \mathrm{~A}$ and $2 \mathrm{~B}$ products for

152 the complete QuikSCAT mission. CERSAT also archives the data from all scatterometer

153 missions and most of the altimeter missions. The WindSat product version used for

154 collocation with QuikSCAT and Jason is the last one delivered in 2006, version 1.9. At

155 the end of July 2006, the SeaWinds project began producing QuikSCAT data to replace

156 version 2.4, using new processing software that features an improved rain flag, a better

157 performance at high wind speeds, and a $12.5 \mathrm{~km}$ wind vector retrievals for level 2 data.

158 This improved data set is used in the present study.

159

160 CERSAT produced the WindSat / QuikSCAT and the WindSat / Jason collocated data 161 set for the complete available WindSat data set, covering February 2003 to November 
1622005 with gaps. Sensors are collocated by pairs, WindSat with QuikSCAT and WindSat

163 with Jason. The data from two sensors are collocated when the time difference is less

164 than one hour and when their ground distance is less than $25 \mathrm{~km}$. All parameters from the

165 L2A (products containing instrumental data among which the radar cross-sections), L2B

166 (products containing geophysical data, i.e., wind vector), SDR (products containing

167 instrumental data among which the brightness temperatures), EDR (products containing

168 geophysical data, i.e., wind vector and atmospheric parameters), or GDR (products

169 containing both low level and geophysical data, i.e., wind vector, radar cross-sections)

170 products are included in the collocated product, depending on which sensors are

171 concerned. For this study, we use two months (February-March 2003) of WindSat /

172 QuikSCAT collocated data for the analysis of the lower level data (radar cross-section

173 and brightness temperature) and four months (February-May 2003) for the analysis of the

174 wind data. Fifteen months (February 2003 - April 2004) of WindSat / Jason collocated

175 data are also examined for comparisons.

177 2.3. The rain flag issue

178 Rain effects on passive and active microwave measurements depend on the sensing

179 frequency and on the sensor measurement geometry. It has been shown (Tournadre and

180 Quilfen, 2003) that the Ku-band QuikSCAT data are affected even by moderate rain rate.

181 Measurements of the ocean surface $\sigma_{0}$ become contaminated for several reasons. Some of

182 the transmitted energy is scattered back towards the scatterometer by the rain and never

183 reaches the ocean surface. Energy backscattered from rain can constitute a significant

184 portion of the measured echo energy. Some of the transmitted energy is scattered and / or 
185 absorbed by the rain and is never measured by the scatterometer. This has the effect of 186 attenuating the echo energy from the ocean. Additionally, the rain roughens the ocean 187 surface and changes its radar cross-section. The total effect results in overestimation of 188 the lower winds and underestimation of the higher winds (Tournadre and Quilfen, 2003).

189 Two rain flags are included in the QuikSCAT Level 2B data to indicate detection of rain 190 contamination. The mp_rain_probability is derived using the Impact-based 191 Multidimensional Histogram (IMUDH) rain-flagging technique developed by Huddelston 192 and Stiles at NASA JPL (2000). Briefly, mp_rain_probability from IMUDH does not flag 193 a specific rain rate but a likelihood that the wind speed is perturbed by more than $2 \mathrm{~m} / \mathrm{s}$ or 194 the direction by more than $15^{\circ}$. The nof_rain_index is derived using the Normalized 195 Objective Function (NOF) rain-flagging technique developed by Mears (2000). It is 196 based upon a simplified version of the standard model function to determine a maximum 197 likelihood estimator and a wind speed for each wind vector cell. In the present study, we 198 use the mp_rain_probability (hereafter RP) since it was shown more efficient (Freilich 199 and Vanhoff, 2006). A threshold of 0.2 for the QuikSCAT RP rain flag is a good 200 compromise to flag the rain-contaminated QuikSCAT data and to avoid QuikSCAT high 201 wind over-flagging (Tournadre and Quilfen, 2005).

202 The WindSat rain flag provided in the EDR products is used in the study. It is based 203 upon a threshold of the $0.2 \mathrm{~mm}$ value for the Cloud Liquid Water content (hereafter 204 CLW). An illustration of the rain flagging problem is provided in Figure 1. Indeed, as 205 discussed in Tournadre and Quilfen (2005) using the precipitation radar data from the 206 Tropical Rainfall Measuring Mission (TRMM), the RP rain flag is not self sufficient 207 under high wind conditions. Due to WindSat / QuikSCAT time and space collocation 
208 errors and high time and space rain cell variability, the WindSat CLW test may fail also 209 to flag the QuikSCAT rain-contaminated data. Figure 1 displays the QuikSCAT wind 210 speed as a function of the RP and CLW parameters (left) and the number of points in 211 each RP / CLW bin (right). The two RP and CLW thresholds used for rain flagging are 212 indicated. High values of RP are associated with mean high winds as measured by 213 QuikSCAT. For RP values larger than about 0.8 the CLW content is greater than $0.2 \mathrm{~mm}$, 214 meaning that these points are clearly associated with rain in stormy conditions and 215 detected by the two flags. Data with RP values between 0.2 and 0.8 and CLW values 216 lower than 0.2 may be associated either to RP over-flagging or to CLW under-flagging. 217 Accounting for the high space / time variability of rain events, possible CLW under218 flagging may be due to the space / time difference between the QuikSCAT and WindSat 219 measurements. Figure 1 (right) shows that for about $6 \%$ of the points the QuikSCAT flag 220 is not set when the WindSat one is. It is impossible to distinguish between WindSat over221 flagging due to space / time collocation errors and QuikSCAT under-flagging. The higher 222 CLW values associated with mean high QuikSCAT winds could be both. For this reason 223 and because both instruments are affected by rain, the two flags are often used jointly in 224 the study: it corresponds to discard $8.3 \%$ of the collocated data.

\subsection{Statistics of the winds in the collocated database}

227 Figure 2 illustrates the spatial distribution of the collocated WindSat / QuikSCAT and 228 WindSat / Jason observations. The WindSat / QuikSCAT collocated database covers 229 most of the ocean with a larger concentration of match-ups at tropical and sub-tropical 230 latitudes than at high latitudes where higher wind speeds are expected. Inversely, the 
231 WindSat / Jason database covers mainly the high latitudes in southern oceans. This is

232 inherent to the sensor geometries and orbital configuration. As a consequence, the results

233 obtained in this study should be carefully analyzed with respect to these non uniform 234 geographical distributions.

235 Figure 3 (top) shows the distribution of the QuikSCAT and WindSat retrieved wind 236 speed and direction for the collocated database, along with the National Centers for 237 Environmental Prediction (NCEP) model results (these histograms include only the pixels 238 for which the WindSat wind speeds are estimated, i.e., excluding the rainy pixels). As

239 expected, the wind speed distribution peaks around $7 \mathrm{~m} / \mathrm{s}$, with limited match-ups above $24015 \mathrm{~m} / \mathrm{s}$, regardless of the wind information sources. The wind direction with respect to the 241 North has two peaks, a large one around $270^{\circ}$ (easterly winds) and a weaker one around $24290^{\circ}$ (westerly winds). The bottom panels on Figure 3 zoom on the high wind tail of the 243 distribution and show that westerlies dominate for high wind speeds. The population of 244 high wind speed retrieved by QuikSCAT is lower than the one estimated from the other 245 sources.

247 3. Sensitivity of the passive and active measurements to the surface wind 248 and comparison with semi-empirical models

249 The sensitivities of the active and passive instruments to the wind vector are analyzed 250 from the satellite observations and compared with semi-empirical models. In this section, 251 only the non-rainy observations are considered, as flagged from both QuikSCAT and 252 WindSat (pixels declared rainy by QuikSCAT or WindSat are not considered). 


\section{3.1. The active responses}

256 Asymptotic models (small perturbation and small slope approximation at first order,

257 Kirchoff approximation or two-scale model) used to predict the normalized radar cross258 section of the sea surface generally fail to reproduce in details backscatter radar 259 measurements. In particular, the predicted polarization ratio versus incidence angle and 260 azimuth angle is not in agreement with experimental data. This denotes the inability of

261 the standard models to fully take into account the roughness properties with respect to the 262 sensor configuration (frequency, incidence, and polarization).

263 One of the models (Mouche et al., 2007a) used in this study considers the latest 264 improvements obtained in the field of approximate scattering theories of random rough 265 surfaces using the local and resonant curvature approximations (RCA). The RCA model 266 is based on an extension of the Kirchoff approximation up to first order to relate 267 explicitly the curvature properties of the sea surface to the polarization strength of the 268 scattered electromagnetic field. As shown in Mouche et al. (2007a), dynamically taking 269 into account the sea surface curvature properties is crucial to better interpret normalized 270 radar cross-section and polarization ratio sensitivities to both sensor characteristics and 271 geophysical environment conditions. The validation of the RCA model, presented in 272 Mouche et al. (2007b), makes use of NSCAT Ku-band scatterometer data and aircraft C273 and X-band data acquired during stormy conditions. It shows significant improvement 274 obtained in modelling the polarization ratio with the RCA model as compared with the 275 classical approaches. 
276 The second model used to compare with QuikSCAT data assumes a decomposition for 277 the sea surface. Following Quilfen et al. (1999), Kudryavtsev et al. (2003) decomposed 278 the normalized radar cross section $\left(\sigma_{0}\right)$ as a sum of two terms. The regular surface is 279 associated with the Bragg scattering theory whereas zones of enhanced roughness 280 associated to the presence of individual breakers contribute to the radar signal through 281 non polarized, scalar, contributions. The Bragg scattering theory is taken into account by 282 a two-scale model. Note that this model has also been developed to corroborate the 283 NSCAT data.

284 Figure 4 presents the comparison between the QuikSCAT normalized radar cross285 section $\sigma_{0}$ and those estimated using the RCA and Kudryavtsev models, as a function of 286 wind speed. $\sigma_{0}$ increases quickly with the wind speed at low to moderate winds, then 287 saturates with increasing wind speed. The RCA model indicates a full saturation, while 288 the data still show some sensitivity with increasing wind speed. The Kudryavtsev model 289 fits the data slightly better at high winds. Inclusion of enhanced roughness areas (linked 290 to breakers) in the surface description certainly helps increase the $\sigma_{0}$ sensitivity to high 291 winds. The modeled and measured polarization differences are in good agreement for 292 both models, although larger than shown in the data beyond $25 \mathrm{~m} / \mathrm{s}$ for the Kudryavtsev 293 model. It decreases with increasing wind speed from moderate to about $20 \mathrm{~m} / \mathrm{s}$, because 294 the $\mathrm{HH}$ polarization shows slightly better sensitivity with increasing winds. The 295 Kudryavtsev model reproduces the crossing of the $\mathrm{HH}\left(46^{\circ}\right.$ incidence angle) and VV $\left(54^{\circ}\right.$ 296 incidence angle) curves near $20 \mathrm{~m} / \mathrm{s}$. Faster decreasing sensitivity of the $\sigma_{0} \mathrm{VV}$ with 297 increasing wind speed beyond $25 \mathrm{~m} / \mathrm{s}$ was also found by Fernandez et al. (2006) using 298 airborne scatterometer and radiometer data during tropical cyclone events. They 
299 measured approximately a $4 \mathrm{~dB}(2 \mathrm{~dB}) \sigma_{0}$ increase at $\mathrm{HH}(\mathrm{VV})$ for winds increasing 300 from 25 to $60 \mathrm{~m} / \mathrm{s}$.

301 The dependence of the mean $\sigma_{0}$ on the wind direction is shown in Figure 5, for VV 302 (top panel) and HH (bottom panel) polarizations, for the RCA model (blue curves) and 303 the data (red curves), at 6,14 , and $22 \mathrm{~m} / \mathrm{s}$. Only the RCA model results are presented for 304 the anisotropic part because the Kudryavtsev model in its present form does not account 305 for a wind speed dependence of the azimuthal modulation. The data and the RCA model 306 are in relative good agreement at $\mathrm{HH}$ polarization, but the amplitudes of the azimuthal 307 modulation differ significantly at VV polarization. The RCA model indicates dramatic 308 increase of the modulation with increasing wind speed while data feature slightly 309 decreasing modulation. This is also true at $\mathrm{HH}$ polarization, but to a smaller extent. Such 310 apparent discrepancies are mainly due to the statistical surface description used to 311 compute the RCA predictions. Adjustments could certainly be made but are beyond the 312 scope of this study. RCA predicts larger HH cross-section than any other asymptotic 313 scattering model and fits the measurements better. Moreover, the RCA model tends 314 towards a Kirchoff asymptotic relation at high winds, i.e. the sea surface polarization 315 sensitivity strongly decreases. At the extreme, both VV and $\mathrm{HH}$ predictions match. 316 Careful analysis shall be directed to data showing larger $\mathrm{HH}$ measurements than VV 317 ones. Indeed, this necessarily indicates distinct scattering mechanisms to be possibly 318 attributed to breaking event effects. 


\section{3.2. The passive responses}

323 The passive microwave observations are sensitive to the sea surface as well as to the 324 atmosphere. To quantify the brightness temperature $(\mathrm{Tb})$ behaviour, we computed their

325 mean values averaged into wind speed bins and for three different integrated water vapor 326 (WV) ranges. This is illustrated in Figures 6 and 7. Only the three lower frequencies are 327 described in these figures since they are less affected by the atmosphere. The behaviour 328 of all 5 frequencies will be described later in this section. Figure 6 displays the mean 329 values using the WindSat / Jason database, where the wind speed reference is the 330 ECMWF one and the WV reference is either the WindSat one (solid lines) or the Jason 331 Microwave Radiometer one (JMR, dashed lines) for comparison purpose. Figure 7 332 displays the same features with the QuikSCAT wind speed and the WindSat WV values

333 as references. It can be seen that the results agree very well when using indifferently the 334 Jason or WindSat WV data and the QuikSCAT or ECMWF wind speed. The most 335 striking feature is that the $\mathrm{H}$ polarization is more sensitive to the wind that the $\mathrm{V}$ 336 polarization. The $\mathrm{V}$ polarization also appears related to the water vapor content, 337 especially at 6.8 and $18.7 \mathrm{GHz}$. This is expected from the $18.7 \mathrm{GHz}$ but not from the 6.8 $338 \mathrm{GHz}$ channel: the $6.8 \mathrm{GHz}$ is actually sensitive to the sea surface (SST) temperature that 339 is usually correlated with the integrated water vapor in the atmosphere. From RTTOV 340 model simulations with a wind speed of $7 \mathrm{~m} / \mathrm{s}$ and for a typical tropical atmosphere, the 341 change in $\mathrm{Tb}$ due to a SST increase of $1 \mathrm{~K}$ is of the order of $0.6 \mathrm{~K}$ (resp. $0.4 \mathrm{~K}$ ) at $6 \mathrm{GHz}$ 342 for the $\mathrm{V}$ polarization (resp. H). It is twice less at $18 \mathrm{GHz}$ and keeps decreasing with 343 frequency. Most of the high WV content data are associated with moderate winds and the 344 winds larger than $10 \mathrm{~m} / \mathrm{s}$ are generally associated with low WV values. The H-pol Tb's 
345 increase quickly with the wind speed and do not present any saturation at wind speed 346 greater than $20 \mathrm{~m} / \mathrm{s}$, whatever the WV range. There is roughly a $1 \mathrm{~K}$ per $1 \mathrm{~m} / \mathrm{s}$ slope, 347 slightly larger for winds above $12 \mathrm{~m} / \mathrm{s}$ as it can be seen mainly at 6.8 and $10.7 \mathrm{GHz}$. This 348 change in the slope is much more pronounced in the V-pol data: the Tb's are not very 349 sensitive to wind speed increase from low to moderate winds. Indeed, at $53^{\circ}$ incidence 350 angle (which is close to the Brewster angle for sea water in this frequency range), the V351 pol signal is not very sensitive to the surface roughness. The change in V-pol is 352 essentially due to the presence of foam that changed with wind speed. The foam coverage 353 increase with wind speed is exponential in shape in most models (e. g., Monahan and 354 O'Muircheartaigh, 1986), similar to the observed change in the V-pol signal with wind 355 speed. The V-pol wind speed sensitivity seems reduced in presence of high integrated 356 water vapor content. The $18.7 \mathrm{GHz}$ channel is much more sensitive to the WV content 357 than to the wind speed, especially for V-pol with a difference of roughly $25 \mathrm{~K}$ at $10 \mathrm{~m} / \mathrm{s}$ 358 between the two extreme WV ranges, while it is only $8 \mathrm{~K}$ at lower frequencies.

359 The WindSat / QuikSCAT database is our primary source for comparison between 360 passive and active measurements under severe weather conditions because it contains 361 more high wind speed observations. To further justify the use of QuikSCAT wind speed 362 as reference, rather than NCEP also available in the database, Figure 8 presents the 363 brightness temperature standard deviations (SD's) for wind speed bins, when QuikSCAT

364 and NCEP wind speeds are used as reference. A water vapor threshold of $20 \mathrm{~mm}$ has 365 been applied to minimize the atmospheric contribution to the Tb's variability. The SD's 366 values contain information on the variability of the other geophysical parameters (SST, 367 salinity, waves) into $2 \mathrm{~m} / \mathrm{s}$ bins but also contain information on the correlation between 
368 the chosen reference wind speed and the brightness temperature. The lower the SD's, the

369 better the correlation between wind speed and $\mathrm{Tb}$, the better the wind speed reference. It

370 can be seen that the SD's are generally lower when the satellite winds are used, for winds

371 beyond $10 \mathrm{~m} / \mathrm{s}$. The SD's increase with increasing channel frequency. The lowest SD's

372 obtained with the QuikSCAT winds justify the subsequent use of QuikSCAT for the

373 evaluation of the WindSat radiometric measurements.

$374 \quad$ Figure 9 illustrates the Tb's behavior as a function of wind speed for the five WindSat

375 channels. For comparison purposes, the sea surface emissivity model FASTEM-3

376 (English and Hewison, 1998; Deblonde, 2000) from the RTTOV fast radiative transfer

377 model has been used (Eyre, 1991; Matricardi et al., 2004). The development of the

378 RTTOV fast radiative transfer model is part of the EUMETSAT sponsored NWP-SAF

379 activities. The last RTTOV-8 version includes the capability to simulate polarimetric

380 radiometers (e.g., WindSat). In line with the semi-empirical model developed by

381 Kudryavtsev and his co-authors (2003), FASTEM-3 uses a two-scale ocean roughness

382 approximation and takes explicitly into account emissivity from foam patches. The ocean

383 permittivity is derived from Ellison et al. (1998) and the foam coverage calculated from

384 Monahan and O'Muircheartaigh (1986). The azimuthal dependence from Liu and Weng

$385(2002,2003)$ is adopted in FASTEM-3, but with revised coefficients derived from the

386 model presented by Coppo et al. (1996) that predicts reduced amplitude of the azimuthal

387 dependence. Tb's have been computed for a dry (4 mm of water vapor content and a SST

388 of $\left.10^{\circ} \mathrm{C}\right)$ and a wet (40 mm of water vapor content and a SST of $26^{\circ} \mathrm{C}$ ) atmospheres.

389 From the WindSat observations, dry (wet) cases have been selected using measurements

390 for which the integrated water vapor content is in the 0 to $20 \mathrm{~mm}$ (20 to $60 \mathrm{~mm}$ ) range, 
391 and the distribution has been adjusted in order to obtain a mean SST of $10^{\circ} \mathrm{C}$ and $26^{\circ} \mathrm{C}$

392 for the dry and wet atmospheres, respectively. The general agreement between WindSat

393 and RTTOV is good, although the mean Tb difference for the two water vapor ranges is

394 generally greater for RTTOV, as expected by the fact that the selected atmospheres for

395 the simulations corresponds to extreme cases, especially for the dry atmosphere.

396 However, the sensitivity to the wind speed is well reproduced although there is a faster

397 increase in H-pol at high wind speeds for the model simulation. This difference is channel

398 dependent and is larger at lower frequencies. As previously noted, the model confirms

399 that there is no saturation of the brightness temperatures at high wind speeds. There are

400 few data beyond $25 \mathrm{~m} / \mathrm{s}$, but the RTTOV model indicates continuous increase in Tb's

401 beyond $30 \mathrm{~m} / \mathrm{s}$. This is exclusively due to the foam coverage parameterization, i.e,

402 Monahan and O'Muircheartaigh (1986), and may certainly be questioned, e.g., the foam

403 coverage percentage exceeds $100 \%$ beyond $40 \mathrm{~m} / \mathrm{s}$. It may explain the faster increase of

404 the H-pol RTTOV simulations by comparison with data.

405 The $3^{\text {rd }}(\mathrm{U})$ and $4^{\text {th }}(\mathrm{F})$ Stokes parameters are computed for the $10.7,18.7$, and 37.0

$406 \mathrm{GHz}$ channels. Sensitivity of these parameters to the wind direction has been quantified

407 (Yueh et al., 2006). Figures 10 and 11 further illustrate this sensitivity in case of a dry

408 (Figure 10) and a wet (Figure 11) atmospheres as selected from the data to outline that

409 these parameters are little affected by the atmosphere contrarily to the two first Stokes

410 parameters. The azimuthal modulation increases with wind speed up to $18 \mathrm{~m} / \mathrm{s}$ and does

411 not vary significantly for winds beyond $20 \mathrm{~m} / \mathrm{s}$ (red curves). Still, the scarcity of high

412 wind data does not enable confident estimates of the modulation intensity. A small phase

413 shift is apparent in the signal as the wind speed increases, already noted in Yueh et al. 
414 (2006). The maximum amplitude of $4 \mathrm{~K}(\mathrm{U})$ and about $0.7 \mathrm{~K}(\mathrm{~F})$ at $18.7 \mathrm{GHz}$ for wind 415 speed higher than $16 \mathrm{~m} / \mathrm{s}$ is consistent with the Yueh et al. results. As expected, the $1^{\text {st }}$ 416 harmonic dominates in the $U$ modulation, with decreasing $2^{\text {nd }}$ harmonic modulation with 417 increasing frequency, while the $2^{\text {nd }}$ harmonic is predominant in the $\mathrm{F}$ modulation. The $\mathrm{F}$ 418 signal is less than $0.2 \mathrm{~K}$ at $37.0 \mathrm{GHz}$ and is almost unusable. $\mathrm{U}$ thus exhibits a strong 419 upwind / downwind modulation while F exhibits a strong upwind / crosswind 420 modulation.

421 The azimuthal modulation remains almost unchanged in case of a wet atmosphere 422 (Figure 11) although its amplitude slightly decreases. Sensitivity of the U and F Stokes 423 parameters to the wind direction is not affected by atmospheric contribution, even at 37 424 GHz. From aircraft observations with the WINDRAD instrument (17, 19, and $37 \mathrm{GHz}$ ), 425 Yueh et al. (2006) also observed that the radiometric wind direction information was 426 robust to weather conditions, with similar response from 17 to $37 \mathrm{GHz}$, even at wind 427 speed above $20 \mathrm{~m} / \mathrm{s}$.

428 Figure 12 presents a comparison between WindSat and the azimuthal modulation from 429 the RTTOV model. The model reproduces quite well the azimuthal modulation but shows 430 also systematic differences with the WindSat data. It features much larger amplitudes for 431 F. It predicts an increase of the modulation from low to high winds in agreement with 432 data for $U$ but this increase is not present in the data for F. For F, the RTTOV model 433 modulation is almost the same regardless of the channel whereas the data show much 434 weaker modulation at $37 \mathrm{GHz}$. For U, the RTTOV model modulation is decreasing with 435 increasing frequency whereas the data show nearly constant azimuthal modulation 436 amplitude. The distribution of the first and second harmonics is comparable for $\mathrm{F}$ for 
437 which the upwind / crosswind modulation dominates for both model and data. It differs

438 for $U$ for which the data show increasing (decreasing) upwind / downwind (upwind /

439 crosswind) modulation with increasing frequency whereas RTTOV has the opposite

440 behavior. Finally, but not surprisingly, the disagreement is larger for higher winds for

441 which there are significant differences in the amplitude and phase of model and data

442 azimuthal modulations.

\section{$443 \quad 3.3$ Discussion}

444 It is worth reminding that physical models are generally developed to account for 445 mechanisms taking place under average weather conditions. It is thus not surprising that 446 extrapolation to severe weather conditions does not compare very well with data. 447 However, the good agreements obtained in the mean behavior of the simulations, for both 448 active and passive modes, are stimulating to pursue efforts in the physical modeling field. 449 Note that the RCA model is developed in a way that enables its extension to passive 450 measurements. Such a synthetic tool will help better analyze the active / passive 451 measurements, with a consistent approach under extreme weather conditions.

452 Under high wind conditions, the sea surface is no longer simply related to the wind 453 speed. In winds approaching hurricane strength, an enhanced breaking activity is taking 454 place at the surface of the ocean. Both whitecaps and spray droplets proliferate, as well as 455 intense mixing of the surface waters with turbulent transport of bubbles to depth. 456 Whitecap bubbles and sea spray provide additional surfaces and volumes that may impact 457 the transfer of any quantity normally exchanged at the air-sea interface. The key 458 parameterization to describe the ocean surface dynamics under such extreme conditions is 459 the distribution of the total length of breaking fronts moving with a given speed or having 
460 a certain wavelength scale. As it can be expected, under extreme wind forcing, breaking

461 waves are distributed over a wider range of surface wave scales as compared to more

462 gentle conditions. As larger waves are involved in breaking processes, both foam

463 coverage and foam thickness significantly increase with increasing wind speeds (Reul

464 and Chapron, 2003). This is certainly the main principle leading to passive measurement

465 sensitivities to high wind conditions. Further, spume drops torn off breaking crests are

466 sprayed inside the air flow at higher height, i.e., the larger scale mean height, to possibly

467 significantly affect the turbulent mixing. This latter effect can then lead to acceleration of

468 the air flow and reduction of the surface drag, as suggested by recent wind profiles

469 measurements under hurricane wind conditions (Powell et al., 2003). Consequently,

470 ocean surface passive remote sensing measurements at very high wind speeds are

471 certainly well adapted and mostly controlled by the instrument abilities to directly or

472 indirectly probe the larger wave breaking impacts. Emissivity models as well as

473 measurements predict saturation in foam emissivity, i.e., foam approaches the behaviour

474 of a black body, for sea-foam thickness larger than about 2 times the electromagnetic

475 wavelength (Rose et al., 2002; Reul and Chapron, 2003). Passive measurements below 15

$476 \mathrm{GHz}$, and to lesser extent at higher frequencies, are thus expected to provide interesting

477 measurements under very high wind speeds $(>30 \mathrm{~m} / \mathrm{s})$. This is confirmed by the WindSat

478 measurements. Concerning active measurements, these larger wave breaking signatures

479 as well as foam and bubble impact on the ocean surface dielectric properties have

480 apparently been successfully captured with altimeter measurements (Quilfen et al., 2006).

481 At low incidence angle, large wave geometry can indeed contribute to the signal 482 sensitivity. At backscatter geometry with larger incidence angle, larger wave breakings 
483 have indirect effects to provide a very active source to generate shorter scale roughness 484 (Kudryavtsev and Johannessen, 2004), and thus to maintain the sensitivity of the radar 485 cross-section to wind speed as shown in Figure 3 for the Kudryavstev semi-empirical 486 scattering model. This source may thus somehow compensate the plausible reduction of 487 small scales direct wind generation, associated to the predicted surface drag reduction. 488 Furthermore, sharply crested waves can also directly enhance the mean backscatter 489 measurements, e.g., increasing radar sea spikes. Following these considerations, 490 backscatter measurements will not be fully saturated at very high wind speeds, as 491 confirmed from QuikSCAT or aircraft radar measurements (Fernandez et al., 2006). 492 However, in such a configuration, measurements shall be made at higher incidence, 493 possibly in horizontal polarization. The electromagnetic wavelength choice is not 494 expected to be crucial under extreme conditions to efficiently probe the ocean surface. To 495 avoid precipitation effects, measurements at lower frequencies (C-and L-bands) should 496 be considered. Finally, as the ocean surface is expected to exhibit localized and 497 intermittent processes, both passive and active estimates should not solely rely on the 498 mean instrumental measurement levels. To better characterize the expected randomness 499 of the fluctuating measurements under hurricane conditions, attention could also focus on 500 the higher order statistics, in particular the variance of the measured signals. Fluctuations 501 of both brightness temperatures and radar cross-sections inside stormy area have 502 generally been reported to vary a lot, with the normalized variance of the signals 503 increasing with wind speeds.

504 Comparisons between QuikSCAT and WindSat sensitivity to the wind speed evidence 505 a better sensitivity of the active mode to low and medium winds and more sensitivity to 
506 high wind speed in the passive mode. QuikSCAT sensitivity to winds beyond $20 \mathrm{~m} / \mathrm{s}$, as

507 verified from few field experiments (Fernandez et al., 2006), is low and estimation of

508 extreme events intensity is thus difficult. On the other hand, this study illustrates the very

509 good sensitivity of WindSat to high winds, as also observed from the nadir viewing

510 Stepped Frequency Microwave Radiometer, SFMR (Fernandez et al., 2006). However,

511 WindSat being sensitive to surface temperature at low frequencies and to water vapor,

512 clouds and rain at higher frequencies, these variables have to be estimated separately.

513 Measurements from channel combinations have certainly to be used to extract the wind

514 information from these passive microwave observations.

515

516 4. Analysis of the retrieved WindSat and QuikSCAT wind vector

517 In this section, the WindSat and QuikSCAT wind retrievals from the operational

518 algorithms are compared, with special focus on the estimates under extreme weather 519 conditions.

\section{$520 \quad$ 4.1. Wind speed comparison}

521 Figure 13 presents the distribution of the WindSat minus QuikSCAT wind speed

522 differences for non-rainy pixels. The mean WindSat minus QuikSCAT difference is 0.26

$523 \mathrm{~m} / \mathrm{s}$ and the standard deviation $0.89 \mathrm{~m} / \mathrm{s}$, with maximum and minimum values of $32 \mathrm{~m} / \mathrm{s}$

524 and $-16 \mathrm{~m} / \mathrm{s}$, respectively. Figure 13 middle and bottom panels show the WindSat and

525 QuikSCAT wind speed distribution, respectively, for data for which the absolute value of

526 the wind speed difference is greater than $8 \mathrm{~m} / \mathrm{s}$. While the distribution of the QuikSCAT

527 wind speed is close the global mean wind speed distribution, the corresponding WindSat

528 distribution is shifted towards high wind speed values. It corresponds mostly to WindSat 
529 wind speed overestimation due to atmospheric effects as already outlined in Freilich and 530 Vanhoff (2006). These data are filtered out for subsequent analysis. The new mean 531 difference and standard deviations are $0.25 \mathrm{~m} / \mathrm{s}$ and $0.79 \mathrm{~m} / \mathrm{s}$, respectively.

532 Mean WindSat speeds binned by QuikSCAT wind speeds are presented in Figure 14, 533 for different WV content intervals. Data are filtered out for rain and for absolute wind 534 speed difference larger than $8 \mathrm{~m} / \mathrm{s}$. The results are quite similar with those obtained in 535 Freilich and Vanhoff (2006), although they did not analyze the effect of water vapor 536 content and used an older version of the WindSat products (NESDIS0). They also found 537 WindSat underestimation of high winds by a larger amount. Figure 14 shows that 538 WindSat winds are lower than QuikSCAT in clear sky and high wind conditions and 539 higher than QuikSCAT winds beyond $15 \mathrm{~m} / \mathrm{s}$ in presence of high water vapor content. 540 The dependence of the comparison on WV may be interpreted as a residual error of the 541 WindSat winds due to multi-parameter retrieval algorithm errors in high winds and water 542 vapor content conditions. For the wind speed range below $15 \mathrm{~m} / \mathrm{s}$, good agreement is 543 found between QuikSCAT and WindSat.

544 Another validation is performed and illustrated in Figure 15 using the Jason and 545 ECMWF winds available using the WindSat / Jason collocated data set. Results are 546 slightly different from those obtained with the QuikSCAT comparison. We find a good 547 agreement between WindSat and Jason or ECMWF wind speed whatever the wind speed 548 range in clear sky conditions, although WindSat winds are slightly higher than the two 549 other wind sources. The dependency of the observed wind speed difference on increasing 550 water vapor is still apparent although less clear because there are few measurements 551 beyond $15 \mathrm{~m} / \mathrm{s}$ wind speed and $20 \mathrm{~mm}$ integrated water vapor. Indeed the collocated 
552 WindSat / Jason measurements are found mainly in mid-latitudes while the collocated

553 WindSat / QuikSCAT measurements are essentially found in tropical areas (Figure 2).

554 To conclude, good agreement is found between the WindSat and the QuikSCAT /

555 Jason / ECMWF winds, except for winds greater than about $17 \mathrm{~m} / \mathrm{s}$ for which WindSat

556 winds are apparently lower than QuikSCAT winds. A residual dependency of the

557 WindSat winds on the water vapor appears for winds beyond $15 \mathrm{~m} / \mathrm{s}$.

\section{4.2. Wind direction comparison}

559 Figure 16, from top to bottom, presents the standard deviation of the difference

560 between the WindSat wind direction and the QuikSCAT, NCEP, and ECMWF wind

561 direction, respectively. Standard deviations (hereafter SD) have been computed for

562 different WV ranges and separately for the tropical and mid-latitude areas in order to

563 account for the mean SST variability. Data for which the direction difference is greater

564 than ninety degrees are discarded before estimation of the SD values. The comparison

565 with the three different data sources shows that the wind direction SD is greater for mid-

566 latitudes. It can be mainly explained as the result of the larger space / time variability in

567 mid-latitude areas, thus associated with larger collocation errors. The SD is larger than

$56820^{\circ}$ at low wind speeds and decreases quickly with increasing wind speed to reach values

569 lower than $10^{\circ}$. SDs computed with QuikSCAT winds decrease faster which denotes the

570 higher QuikSCAT wind direction accuracy for medium winds. The comparison with

571 ECMWF provides still decreasing SD's for increasing wind speed beyond $15 \mathrm{~m} / \mathrm{s}$ while

572 comparison with QuikSCAT and NCEP shows slightly increasing SD values. It must be

573 noted that there are few ECMWF wind speed data beyond $20 \mathrm{~m} / \mathrm{s}$. The comparison

574 between the three data sources show that the SDs are lower than $10^{\circ}$ for winds from 10 
$575 \mathrm{~m} / \mathrm{s}$ to $20 \mathrm{~m} / \mathrm{s}$. This is an excellent agreement, better than the previous WindSat accuracy

576 estimates that were of the order of $15^{\circ}$ in this wind speed range using the former version

577 (NESDIS0) of the WindSat products (Monaldo, 2006; Freilich and Vanhoff, 2006).

578 WindSat version 1.9 product are thus a significantly improved over the former ones.

579 The comparison between QuikSCAT and NCEP shows the effect of WV on the wind 580 direction retrieval accuracy, as for the wind speed analysis. This effect is not clear in the 581 comparison with ECMWF. This is attributed to the different WindSat / QuikSCAT and 582 WindSat / Jason sampling (Figure 2). Although WindSat polarimetric measurements are 583 not much affected statistically by the atmosphere, as shown in Figure 11, the higher 584 scatter observed for higher water vapor content is certainly associated with the low signal 585 to noise ratio for polarimetric measurements. Indeed the azimuthal signal is of the order 586 of a few Kelvin. It is also not surprising that the mean SST conditions influence the 587 magnitude of the scatter to induce differences in the comparison between WindSat and 588 QuikSCAT, and WindSat and Jason measurements. Moreover, any error in the estimation 589 of one of the other parameters (wind speed, WV, SST) will affect the wind direction 590 retrieval of the multi-parameter retrieval process.

591 Figure 17 illustrates the difficulty of WindSat wind vector retrieval under stormy 592 conditions. The top left (right) panel gives the rain free QuikSCAT (WindSat) wind field 593 using the standard rain flag for each product. The bottom left (right) panel gives the 594 WindSat integrated water vapor content (rain rate). The $0.2 \mathrm{~mm}$ threshold on the cloud 595 liquid water content eliminates large interesting parts of the storm in the WindSat 596 estimates. Despite this severe screening, there are still pixels with anomalous wind speed 
597 values on the south side of the storm. WV is equal or greater than $50 \mathrm{~mm}$ over the

598 displayed area. Wind vector retrieval under stormy conditions thus remains a challenge.

600 5. Statistical analysis of the information content of the satellite 601 observations for surface wind retrieval under extreme conditions

602 Different algorithms have been developed to retrieve the wind speed and direction

603 from the WindSat observations, ranging from physical models based on simulations to

604 purely statistical schemes relying on collocations with buoys. All the channels are not 605 systematically used. For instance, Bettenhausen et al. (2006) used a two step variational 606 estimation coupled to an efficient forward physical model to estimate first the wind 607 speed, the water vapor and liquid columns, and the surface temperature, and then the 608 wind direction. $\mathrm{T}_{\mathrm{H}}$ at $6.8 \mathrm{GHz}$ and $\mathrm{T}_{\mathrm{F}}$ at $37 \mathrm{GHz}$ are excluded. On the other hand, Brown 609 et al. (2006) developed an empirical wind vector retrieval scheme based on collocation 610 between QuikSCAT and WindSat.

611 In order to assess the potential of the passive and active microwave observations for 612 wind speed retrieval at high wind speeds, we attempt to reproduce the QuikSCAT wind 613 speed (assumed to be the reference wind speed) with different observation combinations. 614 A multi-linear regression algorithm is adopted. In a preliminary attempt, the training data 615 set used the natural wind speed distribution in the initial database (Figure 3). This 616 resulted in large biases in the retrieval of the high wind speed, due to the heavy weight of 617 wind speeds around $7 \mathrm{~m} / \mathrm{s}$ in this database. It was thus decided to weight the contribution 618 of the different wind speed to obtain the same proportion of all wind speed categories in 619 the database. The following results are obtained with this 'uniformed' database. For each 
620 observation combination, the statistics of the difference with the expected winds are

621 calculated. They are a measure of the potential of this specific combination to retrieve

622 wind speed. These statistics are examined under high wind speed and rainy situations, in

623 order to assess the robustness of the retrieval under these conditions.

624 Figure 18 shows the results of the retrieved Windsat wind speed as compared to the 625 operational QuikSCAT wind speed (QuikSCAT wind speed minus the new estimated 626 wind speed) using 1) all the WindSat channels, 2) the WindSat channels without the 6.8 $627 \mathrm{GHz}, 3)$ WindSat without the 6.8 and $10.7 \mathrm{GHz}$ channels, 4) all WindSat and QuikSCAT 628 observations together, 5) for comparison purposes, the wind speed provided in the 629 standard Windsat products. Table 1 gives the statistics of the estimates separating the 630 rainy and non-rainy cases, and the high wind speeds. Note that the statistics presented in 631 Figure 18 and in Table 1 are calculated on the original database, not on the 'uniformed' 632 database. As expected from the 'uniformed' database used for the training of the 633 algorithm, the performance of the retrieval is rather equivalent for all wind speed ranges. 634 The WindSat observations reproduce well the QuikSCAT wind speed up to $25 \mathrm{~m} / \mathrm{s}$. 635 Above $20 \mathrm{~m} / \mathrm{s}$, part of the discrepancy comes from the lack of high wind speed in the 636 database: although the database has been 'uniformed' for the training of the statistical 637 algorithm, at high wind speeds, the same samples are used many times, thus the 638 variability of the sample is not natural and might be unrealistic. However, it shows that 639 contrarily to the original algorithm that are tuned to be optimum for the most probable 640 winds (around $7 \mathrm{~m} / \mathrm{s}$ ), this simple algorithm performs well in the upper wind speed range, 641 above $15 \mathrm{~m} / \mathrm{s}$. Given that the observations are sensitive to the wind speed without 642 saturation to high wind, optimized algorithms designed for high wind speed conditions 
643 can be developed and this little experiment proves it. Nevertheless, note that a residual

644 bias is observed for the most common winds around $7 \mathrm{~m} / \mathrm{s}$ with the simple algorithm 645 developed here (overestimation of the retrieved wind as compared to the QuikSCAT

646 reference): it would be possible to develop different wind speed algorithms, depending

647 upon the wind speed ranges, based on a prior classification of the situations. From Figure

64818 , it appears that the $6 \mathrm{GHz}$ channels do not provide significant additional information

649 (with or without these channels, the retrievals are very similar), but the $10 \mathrm{GHz}$ channels

650 have a significant impact. Adding QuikSCAT to the WindSat observations does not

651 significantly change the results (note that if in Table 1 the rms is worse with QuikSCAT

652 than without it is related to the fact that the algorithm is not trained on the database that is

653 used to calculate the statistics, otherwise, adding information would make the statistic

654 similar or better).

\section{6. Conclusion and perspectives}

657 Under extreme weather conditions, accurate wind vector retrieval is difficult for four 658 main reasons. First, under high wind conditions, the sea surface is no longer simply 659 related to the wind speed. Breaking activity and associated whitecaps and spray taking 660 place at the surface of the ocean and interfere with the satellite response. There are 661 ongoing efforts to understand and model these complex effects. Second, both physical 662 models and wind vector retrieval methods have been primarily developed for medium 663 range wind conditions, that are much more common. Third, extreme weather conditions 664 are generally associated with clouds and rain that contaminate the satellite signal. The 665 impact of these perturbations increasing with increasing observation frequency. Freilich 666 and Vanhoff (2006) set the tone: 'Accurate wind retrievals are not possible at all in heavy 
667 rain'. Not only the rain in the atmosphere absorbs and scatters the microwave response

668 but the rain drops on the ocean surface also affect the ocean roughness. Fourth, in high

669 wind conditions, the wind speed can vary greatly over the satellite footprint. Therefore,

670 the retrieval is really an average over the footprint and one often miss to measure the

671 extreme winds because of this smoothing effect.

672 However, this study shows that wind vector retrieval under extreme condition is 673 feasible. Comparisons between QuikSCAT and WindSat observations show that the 674 active mode is more sensitive to low and moderate winds whereas the passive mode 675 responds better to high wind speeds. Although the WindSat observations are affected by 676 water vapor, cloud, and rain, especially at and above $18 \mathrm{GHz}$, the measurements are 677 sensitive to wind speed even at high wind speed. Contrarily to the active instrument, there 678 is no saturation at high winds and the sensitivity clearly increases for winds above 20 $679 \mathrm{~m} / \mathrm{s}$. Developments of wind retrieval from WindSat observations could thus certainly be 680 adapted to high wind speeds. As a first attempt, a multi-linear regression retrieval is 681 presented in this study to show consistent and encouraging results, even under extreme 682 conditions (high rain rate). For the wind direction, the amplitude of the azimuthal 683 modulation in the active mode decreases with increasing wind speed, while it increases 684 for the passive measurements. This also favours the use of WindSat for the estimation of 685 the direction of high winds. However, given the limited amplitude of the signals, a good 686 instrument accuracy has to be achieved (of the order of $0.2 \mathrm{~K}$ ) to retrieve accurate wind 687 direction from the polarimetric measurements (English et al., 2006). We only briefly 688 tested the joint use of passive and active mode for wind speed retrieval. This possibility 
689 should be examined further, to benefit from the different sensitivity of the two modes to 690 the various wind speed ranges.

691 The main problem for the development of retrieval methods adapted to high wind 692 speed lies in the lack of wind references under extreme conditions. This implies the need 693 to develop dedicated collocated database. This also encourages the use of sea state 694 information to trace efficiently the resulting scattered large swell conditions from 695 localized extreme conditions, to better analyze extreme events intensity.

696

697 Acknowledgments:

698 This study has been partly funded by the European Space Agency in the frame of the 699 Extreme Weather Events project. The Windsat data has been provided by the Naval 700 Research Laboratory in the frame of the Windsat calibration/validation activities. The 701 CERSAT, IFREMER, has produced the Windsat/QuikScat/Jason collocated products. 702 The authors would like to thank Pascal Brunel and Stephen English for their help with the 703 RTTOV model, Fuzhong Weng for providing the Liu and Weng emissivity model, and 704 Jean Tournadre for helpul discussion.

705

706

707

708

709

710

711 


\section{References}

713 Adams, I. S., C. C. Henneon, W. L. Jones, and K. A. Ahamad (2006), Evaluation of

714 hurricane ocean vector winds from WindSat, IEEE Trans. Geo. Sc. Remote Sens., 44, $715 \quad 656-667$.

716 Bettenhausen, M. H., G. K. Smith, R. M. Bevilacqua, N.-Y. Wang, P. W. Gaiser, and S.

717 Cox (2006), A nonlinear optimization algorithm for WindSat wind vector retrievals,

718 IEEE Trans. Geo. Sc. Remote Sens., 44, 597-610.

719 Brown, S. T., C. S. Ruf, and D. R. Lyzenga (2006), An emisisvity-based wind vector

720 retrieval algorithm for the WindSat polarimetric radiometer", IEEE Trans. Geo. Sc.

$721 \quad$ Remote Sens., 44, 611-621.

722 Coppo, P., J.T. Johnson, L. Guerriero, J.A. Kong, G. Macelloni, F. Marzano, P.

723 Pampaloni, N. Pierdica, D. Solimini, C. Susini, G. Tofani, and Y. Zhang (1996),

724 Polarimetry for passive remote sensing, ESA contract 1146/95/NL/NB, Final report.

725 Deblonde, G. (2000), Evaluation of FASTEM and FASTEM-2, NWP SAF Report,

726 http://www.metoffice.com/research/interproj/nwpsaf/rtm/.

727 Ellison, W., A. Balana, G. Delbos, K. Lamkaouchi, L. Eymard, C. Guillou, and C.

728 Prigent (1998), New permittivity measurements and interpolation functions for natural

729 sea water, Radio Sc., 33, 668-685.

730 English, S. J., and T.J. Hewison (1998), A fast generic millimetre wave emissivity

731 model, Microwave Remote Sensing of the Atmosphere and Environment Proc. SPIE

$7323503,22-30$. 
733 English, S., B. Candy, A. Jupp, D. Beddington, S. Smith, and A. Holt (2006), An

734 evaluation of the potential of polarimetric radiometry for numerical weather prediction 735 using QuikSCAT, IEEE Trans. Geo. Sc. Remote Sens., 44, 668-675.

736 Eyre, J. R. (1991), A fast radiative transfer model for satellite sounding systems, 737 ECMWF Research Dept. Tech. Memo.176 (available from the librarian at ECMWF).

738 Fernandez, D. E., J. R. Carswell, S. Frasier, P. S. Chang, P. G. Black, and F. D. Marks

739 (2006), Dual-polarized C- and Ku-band ocean backscatter response to hurricane-force

740 winds, J. Geophys. Res., 111, C08013, doi:10.1029/2005JC003048.

741 Freilich, M. H., and B. A. Vanhoff (2006), The accuracy of preliminary WindSat vector

742 wind measurements: Comparisons with NDBC buoys and QuikSCAT, IEEE Trans.

743 Geo. Sc. Remote Sens., 44, 622-637.

744 Gaiser, P. W., K.M. St Germain, E.M. Twarog, G.A. Poe, W. Purdy, D. Richardson, W.

745 Grossman, W.L. Jones, D. Spencer, G. Golba, J. Cleveland, L. Choy, R.M.

746 Bevilacqua, P.S. Chang (2004), The WindSat spaceborne polarimetric microwave

747 radiometer: Sensor description and early orbit performance, IEEE Trans. Geo. Sc.

$748 \quad$ Remote Sens., 42, 2347-2361.

749 Huddelston, J. N., and B. W. Stiles (2000), Multidimensional histogram (MUDH) rain 750 flag, Jet Propulsion Laboratory, California Institute of Technology.

751 Kudryavtsev, V., and J. Johannessen (2004), Effect of wavebreaking on spectrum of

752 short wind waves, Geophys. Res. Let., 31, L20310.

753 Kudryavtsev V., D. Hauser, G. Caudal, and B. Chapron (2003), Semi-empirical model

754 of the normalized radar cross-section of the sea surface. 1. Background model, $J$.

755 Geophys. Res., 108, 8054, doi: 10.1029/2001JC001003. 
756 Liu, Q., and F. Weng (2002), A microwave polarimetric two-stream radiative transfer

757 model, J. Atmos. Sci., 59, 2396-2402.

758 Liu, Q., and F. Weng (2003), Retrieval of sea surface wind vectors from simulated

759 satellite microwave polarimetric measurements, Radio Sc., 38, 8078,

760 doi:10.1029/2002RS002729.

761 Matricardi, M., F. Chevallier, G. Kelly, and J.N. Thépaut (2004), An improved general

762 fast radiative transfer model for the assimilation of radiance observations, Quat. J.

763 Roy. Meteor. Soc., 130, 153-173.

764 Mears C. (2000), Sea Winds on QuikSCAT normalized objective function rain flag,

765 version 1.2, 13pp, Remote Sensing System, Santa Rosa, Calif.

766 Monahan, E. C., and I. O Muircheartaigh (1986), Whitecaps and the passive remote

767 sensing of the ocean surface, Int. J. Remote Sensing, 7, 627-642.

768 Monaldo, F. M. (2006), Evaluation of WindSat wind vector performance with respect to

769 QuikSCAT estimates, IEEE Trans. Geo. Sc. Remote Sens., 44, 638-644.

770 Mouche, A., B. Chapron, and N. Reul (2007a), Asymptotic theory for ocean surface

771 electromagnetic waves scattering, in press in Waves in Random and Complex Media.

772 Mouche, A., B. Chapron, N. Reul, D. Hauser, and Y. Quilfen (2007b), Importance of the

773 sea surface curvature to interpret the normalized radar cross-section, submitted to $J$.

$774 \quad$ Geophys. Res.

775 Powell, M. D., P. J. Vickery, and T. A. Reinhold (2003), Reduced drag coefficient for 776 high wind speeds in tropical cyclones, Nature, 422, 279-283. 
777 Quilfen, Y., B. Chapron, T. Elfouhaily, K. B. Katsaros, and J. Tournadre (1998),

778 Observations of tropical cyclones by high-resolution scatterometry, J. Geophys. Res., $779 \quad 103,7767-7786$.

780 Quilfen, Y., B. Chapron, A. Bentamy, J. Gourrion, T. Elfouhaily, and D. Vandemark

781 (1999), Global ERS-1/2 and NSCAT observations: upwind/downwind and

782 upwind/crosswind measurements. J. Geophys. Res., 104, 11459-11469.

783 Quilfen, Y., J. Tournadre, and B. Chapron (2006), Altimeter dual-frequency

784 observations of surface winds, waves, and rain rate in tropical cyclone Isabel, $J$.

785 Geophys. Res., 111, C01004, doi:10.1029/2005JC003068.

786 Reul, N., and B. Chapron (2003), A model of sea-foam thickness distribution for

787 passive microwave remote sensing applications, J. Geophys. Res., 108, C10, 3321,

788 doi:10.1029/2003JC001887.

789 Rose, L.A., W.E. Asher, S.C. Reising, P.W. Gaiser, K.M. St Germain, D.J. Dowgiallo,

790 K.A. Horgan, G. Farquharson, and E.J. Knapp (2002), Radiometric Measurements of

791 the Microwave Emissivity of Foam. Trans. Geosci. Rem. Sens., 40, 2619-2625.

792 Tournadre, J., and Y. Quilfen (2003), Impact of rain cell on scatterometer data: 1.

793 Theory and modelling. J. Geophys. Res., 108, C7, 3225, doi:10.1029/2002JC001428.

794 Tournadre, J., and Y. Quilfen (2005), Impact of rain cell on scatterometer data: 2.

795 Correction of Seawinds measured backscatter and wind and rain flagging, J. Geophys.

$796 \quad$ Res., 110, C07023, doi:10.1029/2004JC002766.

797 Yueh, S. H., W. J. Wilson, S. J. Dinardo, and S. V. Hsiao (2006), Polarimetric

798 microwave wind radiometer model function and retrieval testing for WindSat, Trans.

799 Geo. Sc. Remote Sens., 44, 585-595. 
800 WindSat Data Products User's Manual, Version 3.0 (2006), D-29825, Ted Lungu

801 Editor.

802

803

804

805

\begin{tabular}{|c|c|c|c|c|c|c|}
\hline & $\begin{array}{c}\text { rms } \\
\text { (no rain) }\end{array}$ & $\begin{array}{c}\text { mean } \\
\text { (no rain) }\end{array}$ & $\begin{array}{l}\text { rms } \\
\text { (rain) }\end{array}$ & $\begin{array}{l}\text { mean } \\
\text { (rain) }\end{array}$ & $\begin{array}{c}\mathrm{rms} \\
(\mathrm{ws}>15 \mathrm{~m} / \mathrm{s})\end{array}$ & $\begin{array}{c}\text { mean } \\
(\mathrm{ws}>15 \mathrm{~m} / \mathrm{s})\end{array}$ \\
\hline WindSat & 1.56 & -0.75 & 3.12 & -1.54 & 2.98 & -1.75 \\
\hline $\begin{array}{c}\text { WindSat (minus } \\
6 \mathrm{GHz})\end{array}$ & 1.57 & -0.75 & 3.21 & -1.53 & 2.98 & -1.71 \\
\hline $\begin{array}{l}\text { WindSat (minus } \\
6 \text { and } 10 \mathrm{GHz} \text { ) }\end{array}$ & 2.36 & -1.25 & 3.62 & -2.04 & 4.33 & -3.06 \\
\hline $\begin{array}{l}\text { WindSat + } \\
\text { QuikSCAT }\end{array}$ & 1.73 & -0.83 & 3.00 & -1.71 & 2.90 & -1.89 \\
\hline $\begin{array}{l}\text { Operational } \\
\text { WindSat }\end{array}$ & 2.26 & -0.38 & 8.70 & 5.54 & 4.75 & -0.49 \\
\hline
\end{tabular}

806

807 Table 1: The performance of the inversion for the different observation combinations.

808 The results are first presented for the non-rainy cases (WindSat CLW $<0.2 \mathrm{~mm}$ ), for the

809 rainy cases, and finally for the wind speeds above $15 \mathrm{~m} / \mathrm{s}$. Unit in $\mathrm{m} / \mathrm{s}$.

810 

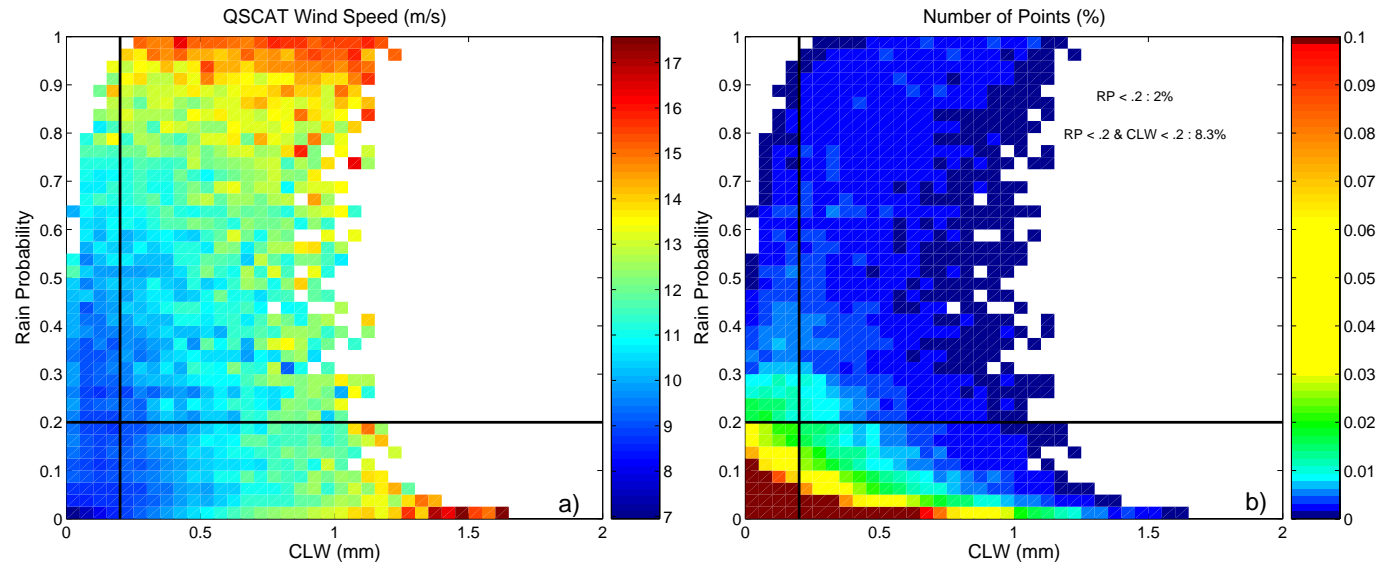

819 Figure 1: a) Mean QuikSCAT wind speed computed in RP / CLW bins and b) associated

820 number of points, as a function of the rain probability (RP) and cloud liquid water content 821 (CLW).

822

823

824

825

826 


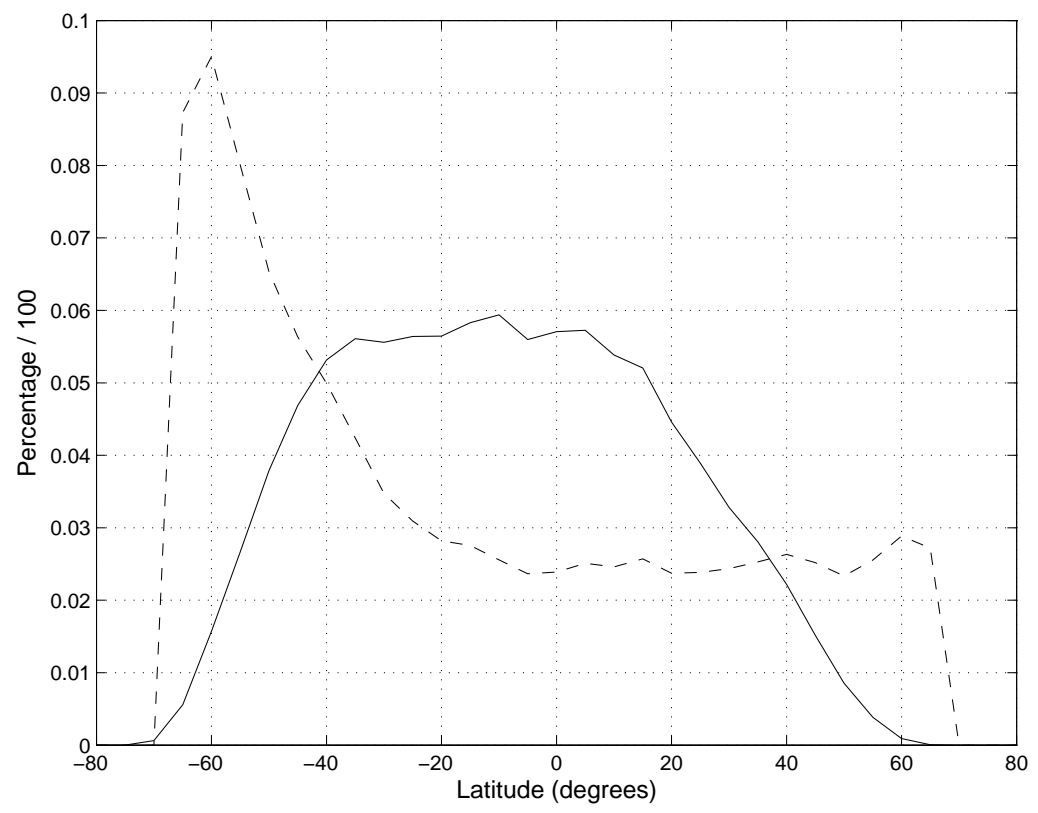

837 Figure 2: Distribution of the collocated WindSat / QuikSCAT (solid line) and WindSat /

838 Jason (dashed line) observations as a function of latitude. 

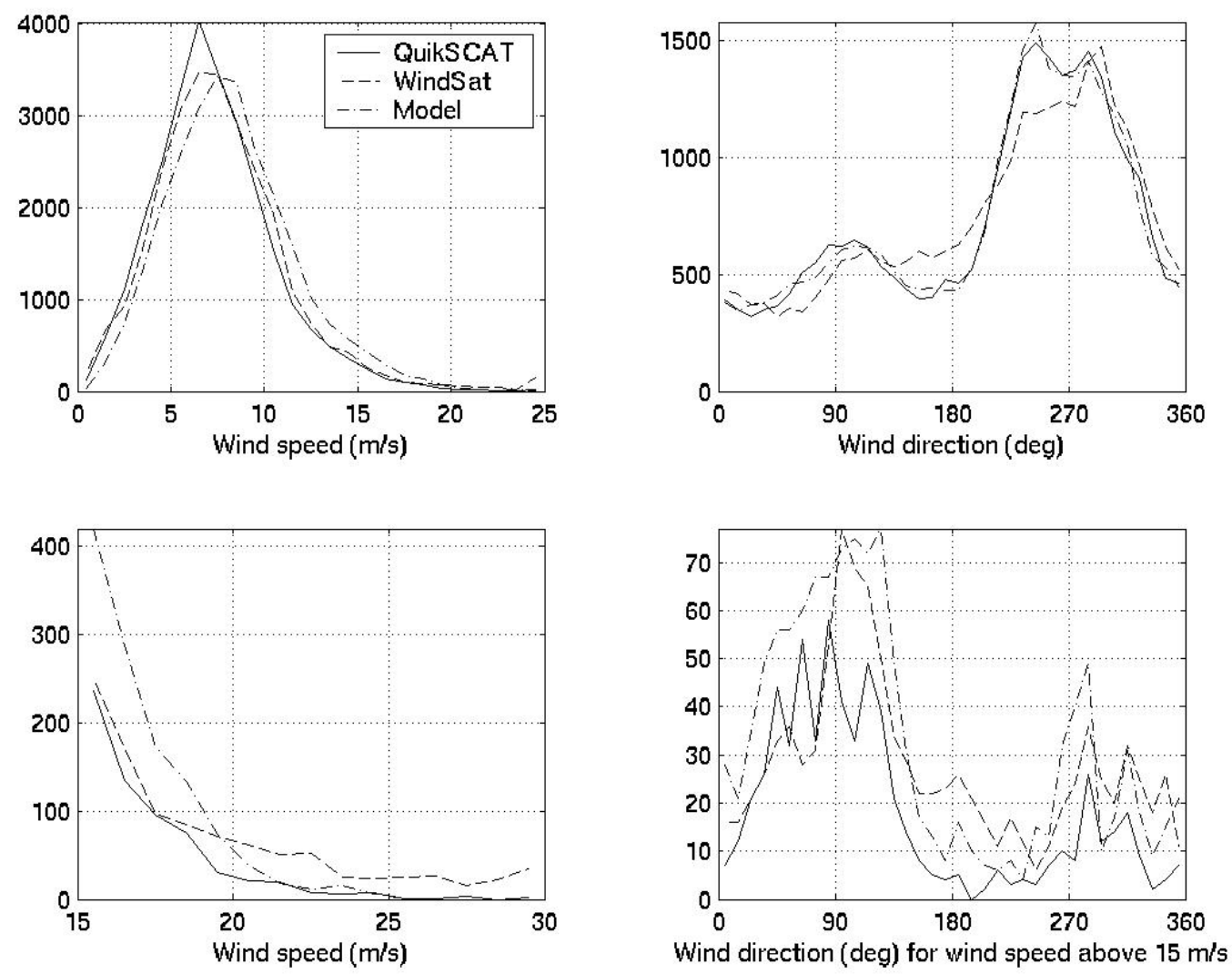

845

846 Figure 3: Distribution of the wind speeds from the collocated database. Histograms are

847 presented for QuikSCAT, WindSat, and the NCEP model estimates.

848

849

850

851

852 


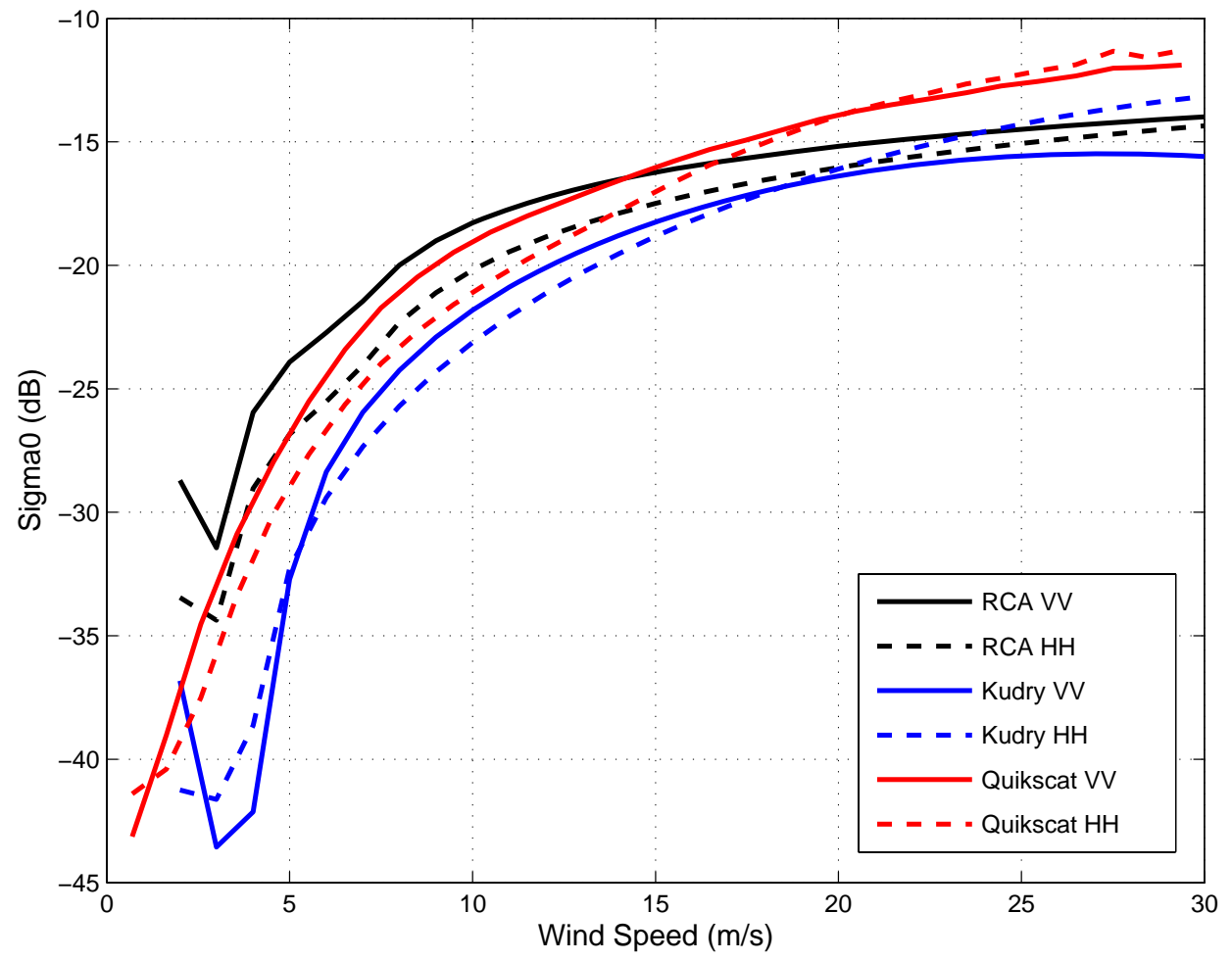

857 Figure 4: Mean Ku-band VV (solid lines) and HH (dashed lines) $\sigma_{0}(\mathrm{~dB})$ computed with

858 the RCA model (black), the Kudryavtsev model (blue), and the QuikSCAT data (red), as

859 a function of wind speed $(\mathrm{m} / \mathrm{s})$.

860

861

862

863

864

865 


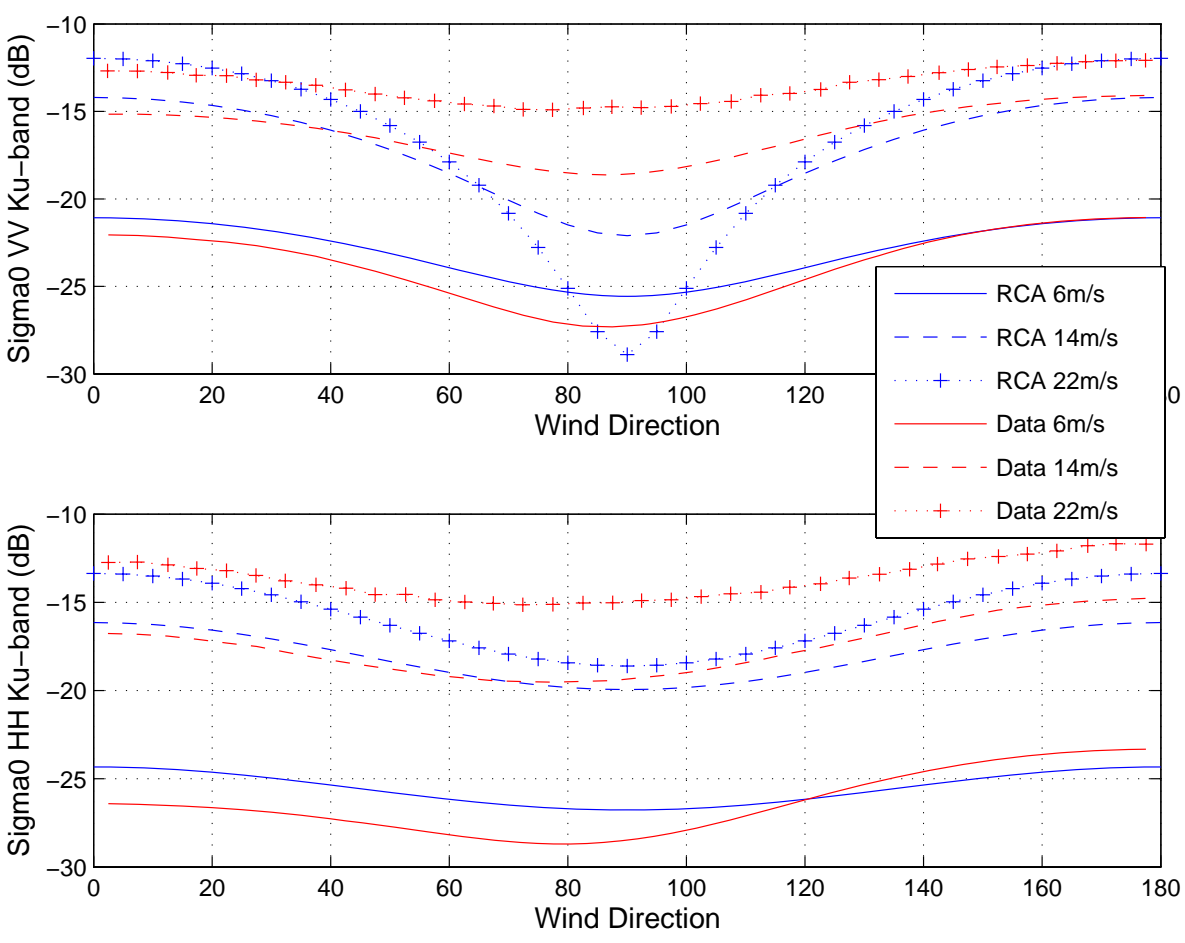

868 Figure 5: Mean Ku-band VV (top panel) and HH (bottom panel) $\sigma_{0}(\mathrm{~dB})$ computed with 869 the RCA model (blue) and QuikSCAT data (red), as a function of the wind direction 870 (degrees), for $6 \mathrm{~m} / \mathrm{s}$ (solid lines), $14 \mathrm{~m} / \mathrm{s}$ (dashed lines), and $22 \mathrm{~m} / \mathrm{s}(+)$ mean wind speed. 

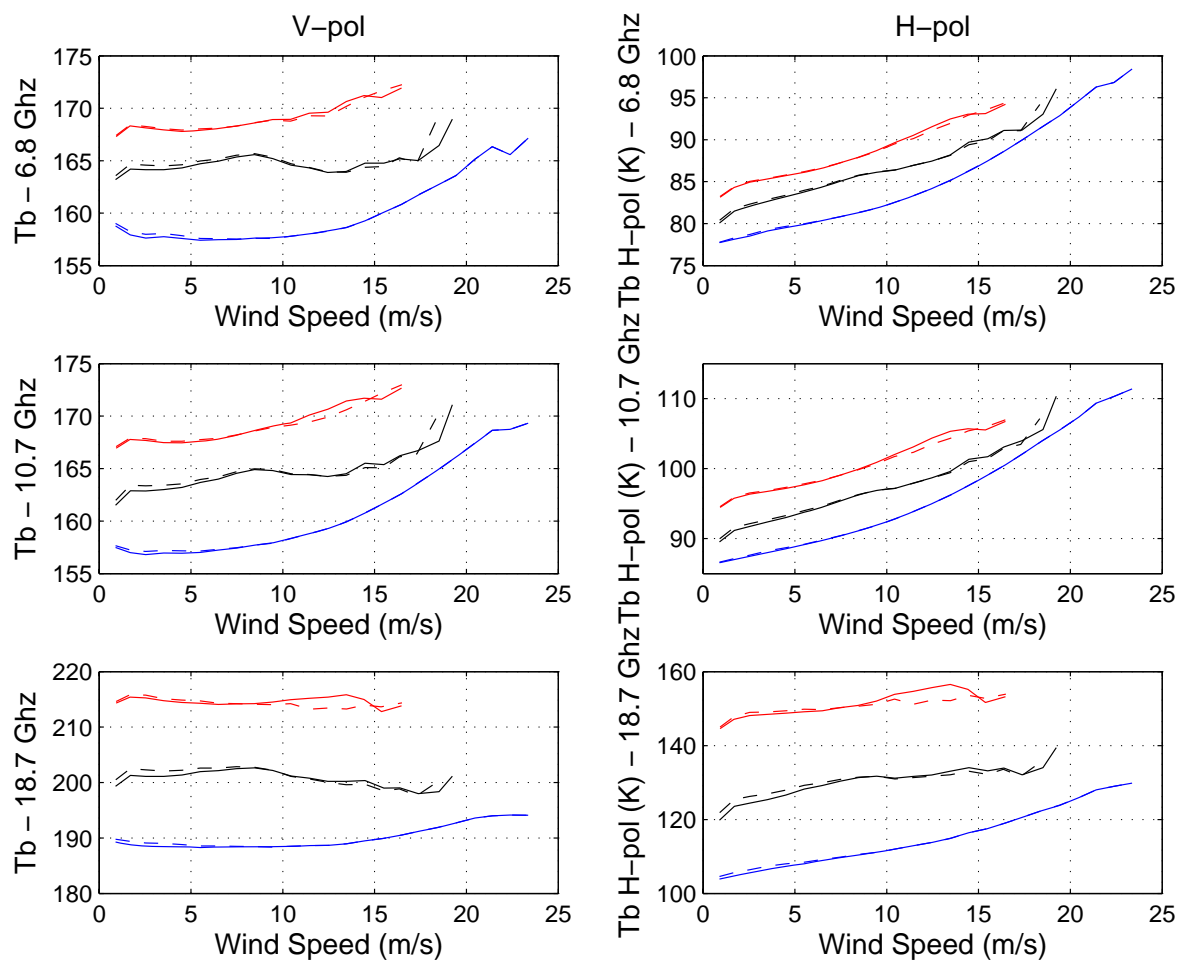

880 Figure 6: Mean V-pol (left panels) and H-pol (right panels) Tb's binned as a function of 881 ECMWF wind speed (m/s), at $6.8 \mathrm{GHz}$ (top), $10.7 \mathrm{GHz}$ (middle), and $18.7 \mathrm{GHz}$ (bottom), 882 and for different integrated water vapor ranges: $0 \mathrm{~mm}<\mathrm{WV}<20 \mathrm{~mm}$ (blue lines), $20 \mathrm{~mm}$ $883<\mathrm{WV}<40 \mathrm{~mm}$ (black lines), and 40mm $<\mathrm{WV}<60 \mathrm{~mm}$ (red lines). WindSat (dashed 884 lines) and Jason microwave radiometer (dashed lines) integrated water vapor data are 885 used.

886 

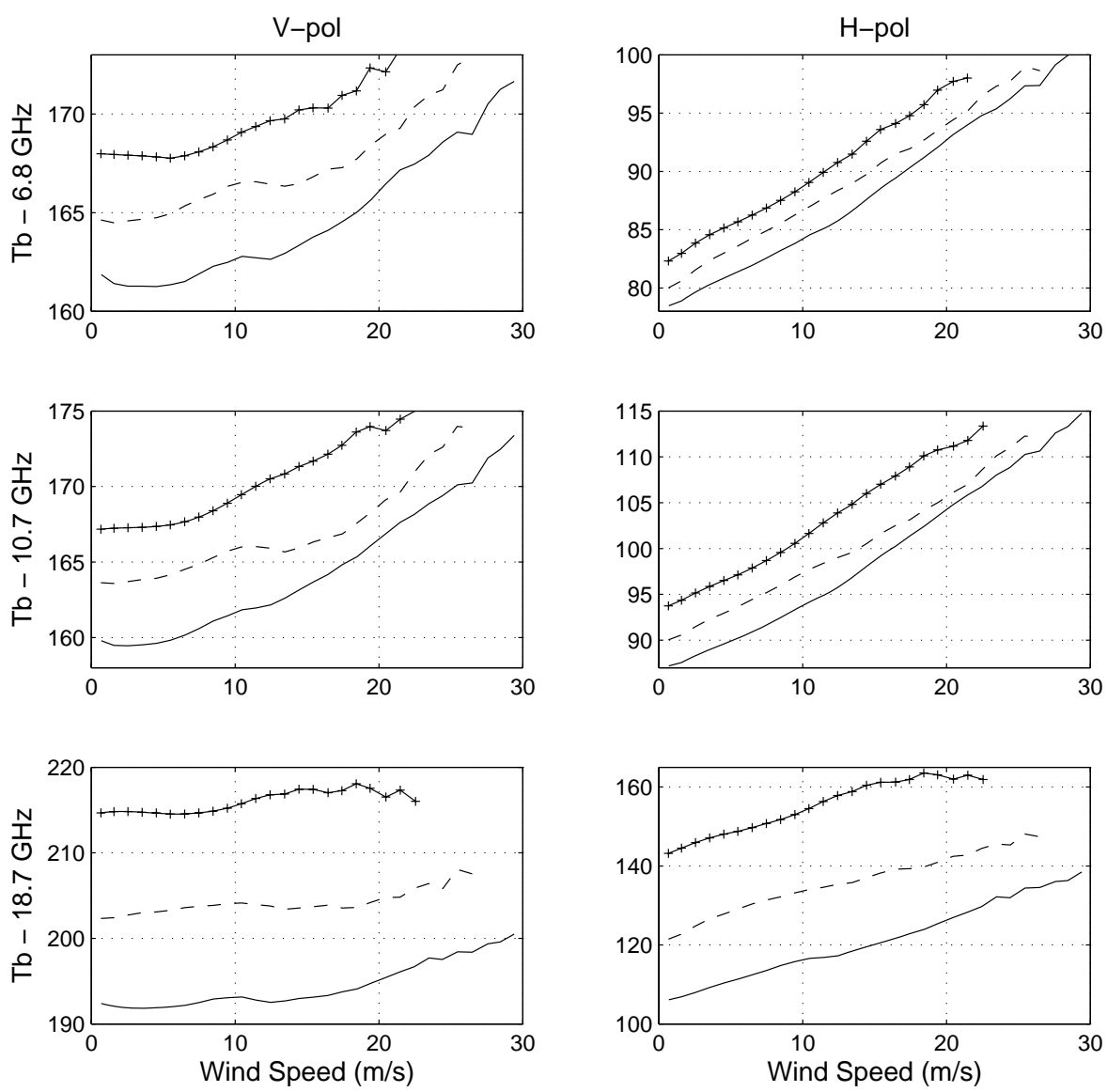

891

892 Figure 7: Mean V-pol (left panels) and H-pol (right panels) Tb's binned as a function of

893 QuikScat wind speed (m/s), at $6.8 \mathrm{GHz}$ (top), $10.7 \mathrm{GHz}$ (middle), and $18.7 \mathrm{GHz}$

894 (bottom), and for different integrated water vapor ranges: $0 \mathrm{~mm}<\mathrm{WV}<20 \mathrm{~mm}$ (solid

895 lines), $20 \mathrm{~mm}<\mathrm{WV}<40 \mathrm{~mm}$ (dashed lines), and 40mm $<\mathrm{WV}<60 \mathrm{~mm}$ (plus signs).

896 WindSat integrated water vapor data are used.

897

898

899

900 


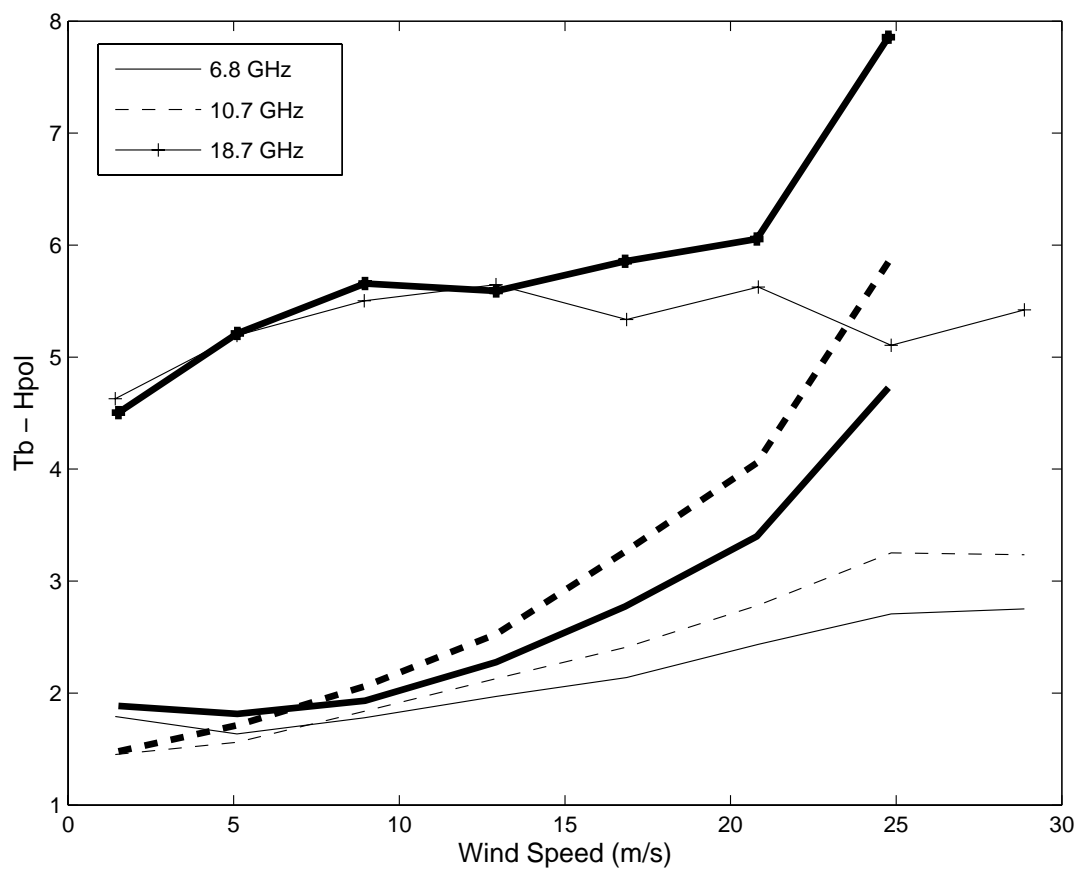

905 Figure 8: H-pol Tbs standard deviations binned as a function of QuikSCAT (thin lines) 906 and NCEP (thick lines) wind speed ( $2 \mathrm{~m} / \mathrm{s}$ bins), at $6.8 \mathrm{GHz}$ (solid lines), $10.7 \mathrm{GHz}$ 907 (dashed lines), and $18.7 \mathrm{GHz}$ (crosses). The integrated water vapor ranges is $0 \mathrm{~mm}<\mathrm{WV}$ $908<20 \mathrm{~mm}$. 

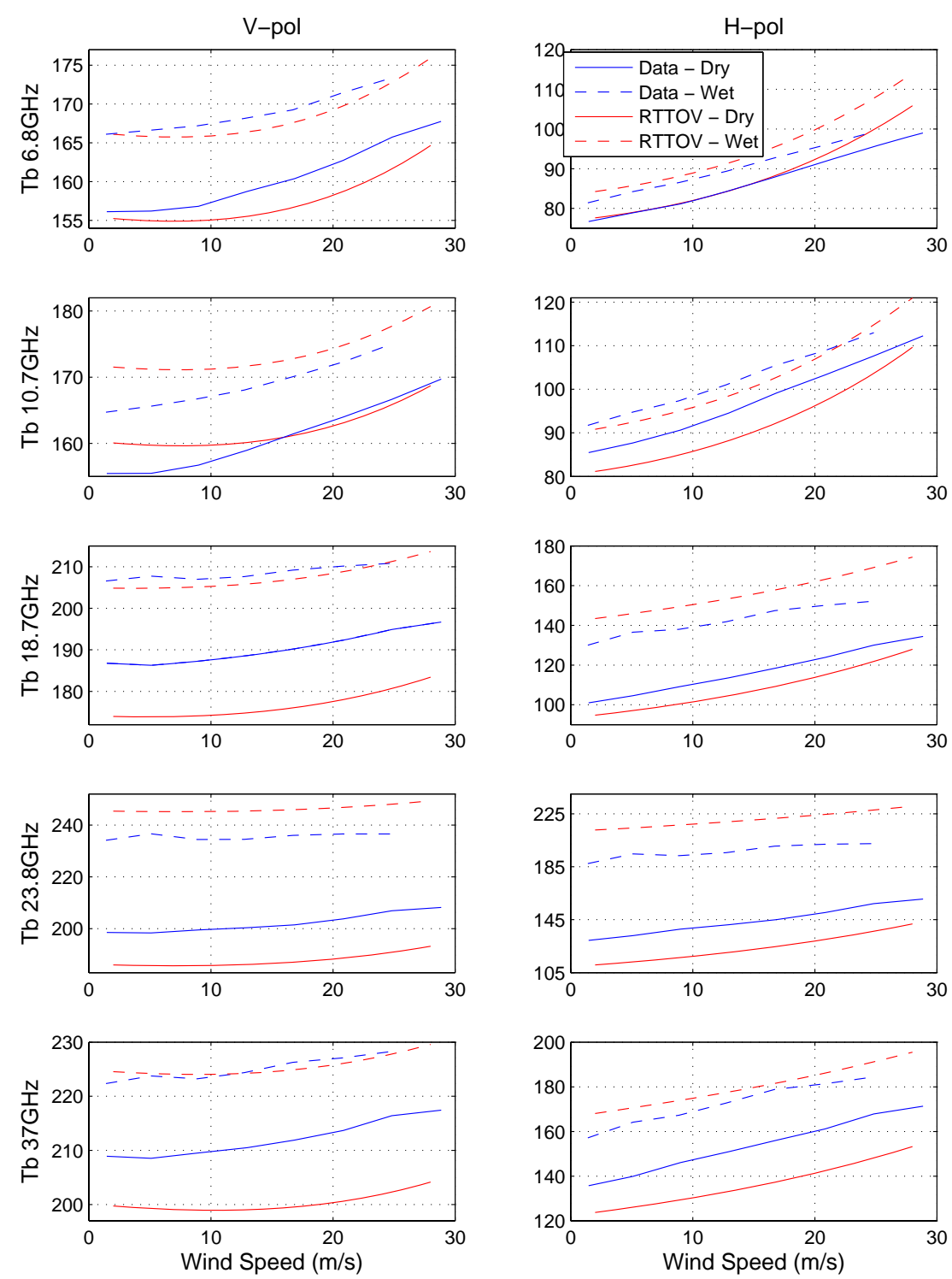

910

911 Figure 9: Mean V (left panels) and $\mathrm{H}$ (right panels) Tb's binned as a function of

912 QuikSCAT wind speed (m/s), at $6.8 \mathrm{GHz}, 10.7 \mathrm{GHz}, 18.7 \mathrm{GHz}, 23.8 \mathrm{GHz}$, and 37.0

$913 \mathrm{GHz}$, respectively from top to bottom, for a dry atmosphere: $0 \mathrm{~mm}<\mathrm{WV}<20 \mathrm{~mm}$ (solid

914 lines), and for a wet atmosphere $20 \mathrm{~mm}<\mathrm{WV}<60 \mathrm{~mm}$ (dashed lines). WindSat data are

915 plotted as blue lines and RTTOV model as red lines. 

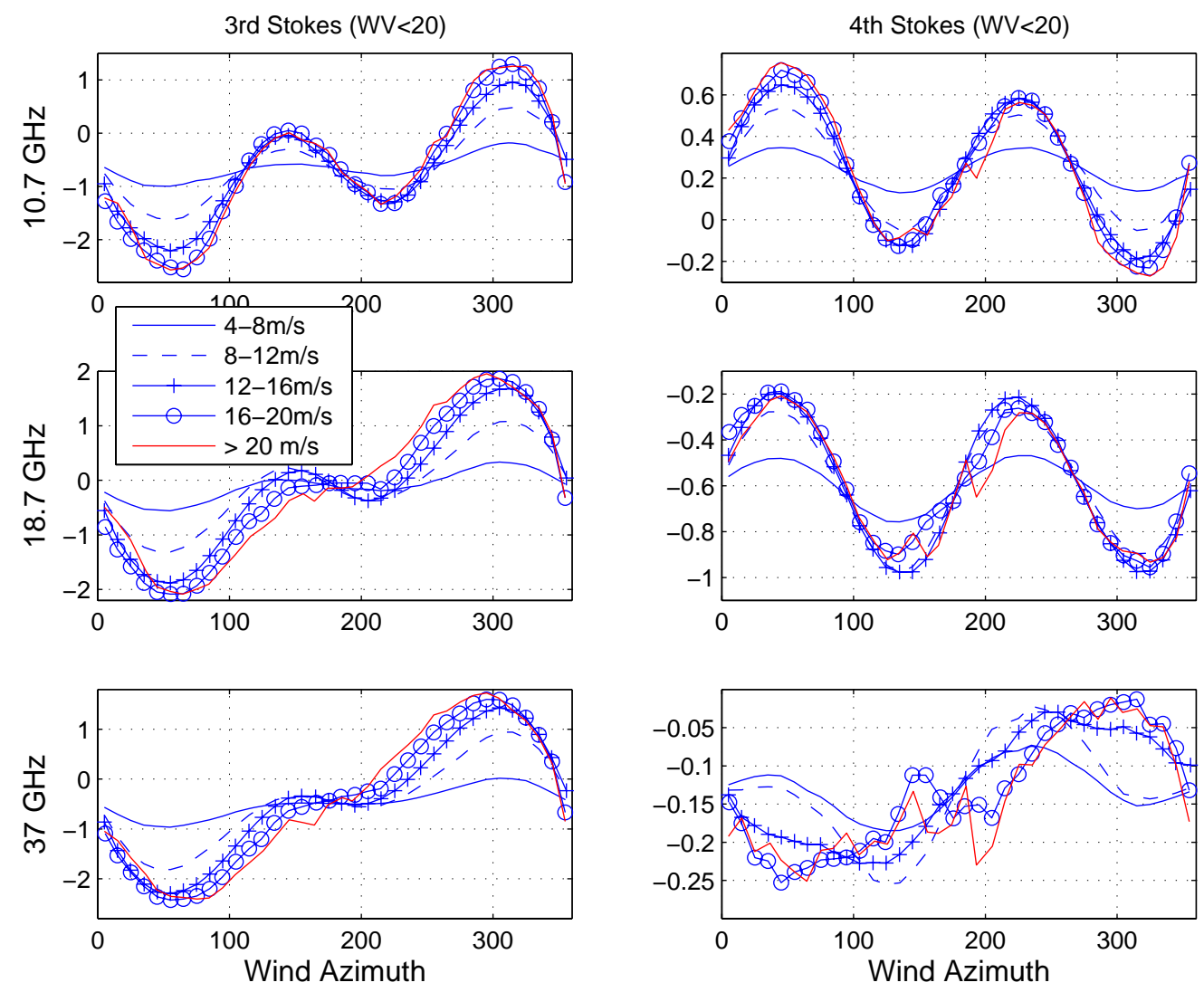

921 Figure 10: Mean $3^{\text {rd }}$ (left panels) and $4^{\text {th }}$ (right panels) Stokes parameters binned as a

922 function of the relative wind direction (degrees), at $10.7 \mathrm{GHz}$ (top), $18.7 \mathrm{GHz}$ (middle),

923 and $37.0 \mathrm{GHz}$ (bottom), and for different wind speed ranges: $4 \mathrm{~m} / \mathrm{s}<\mathrm{WS}<8 \mathrm{~m} / \mathrm{s}$ (solid

924 lines), $8 \mathrm{~m} / \mathrm{s}<\mathrm{WS}<12 \mathrm{~m} / \mathrm{s}$ (dashed lines), $12 \mathrm{~m} / \mathrm{s}<\mathrm{WS}<16 \mathrm{~m} / \mathrm{s}(+), 16 \mathrm{~m} / \mathrm{s}<\mathrm{WS}<$

$92520 \mathrm{~m} / \mathrm{s}(\mathrm{o}), \mathrm{WS}>20 \mathrm{~m} / \mathrm{s}$ (red lines). Integrated water vapor is taken in the range $\mathrm{WV}<$ $92620 \mathrm{~mm}$. 
931

932
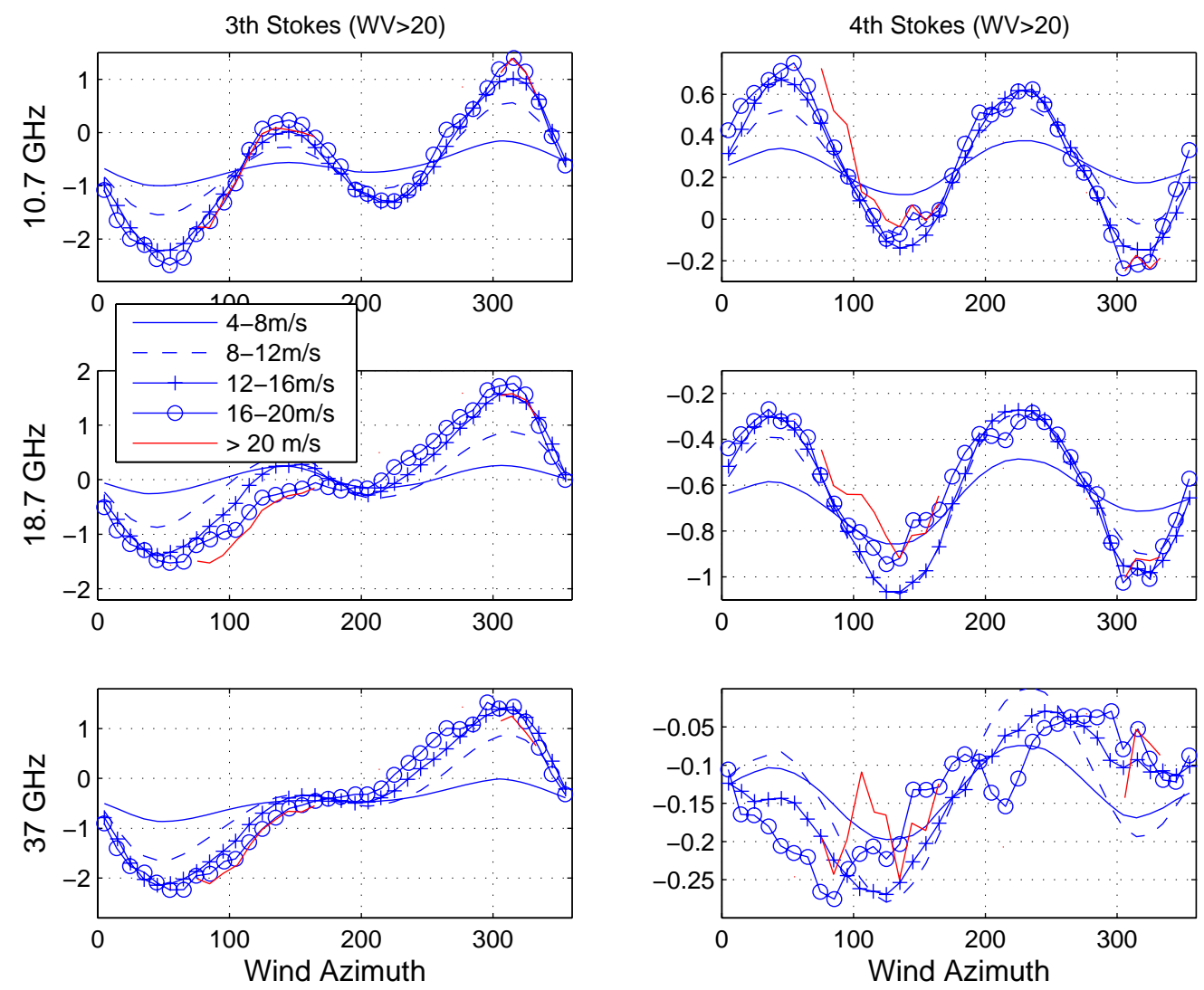

934 Figure 11: Same as Figure 10 with integrated water vapor taken in the range $20 \mathrm{~mm}<$

$935 \mathrm{WV}<50 \mathrm{~mm}$.

936

937 

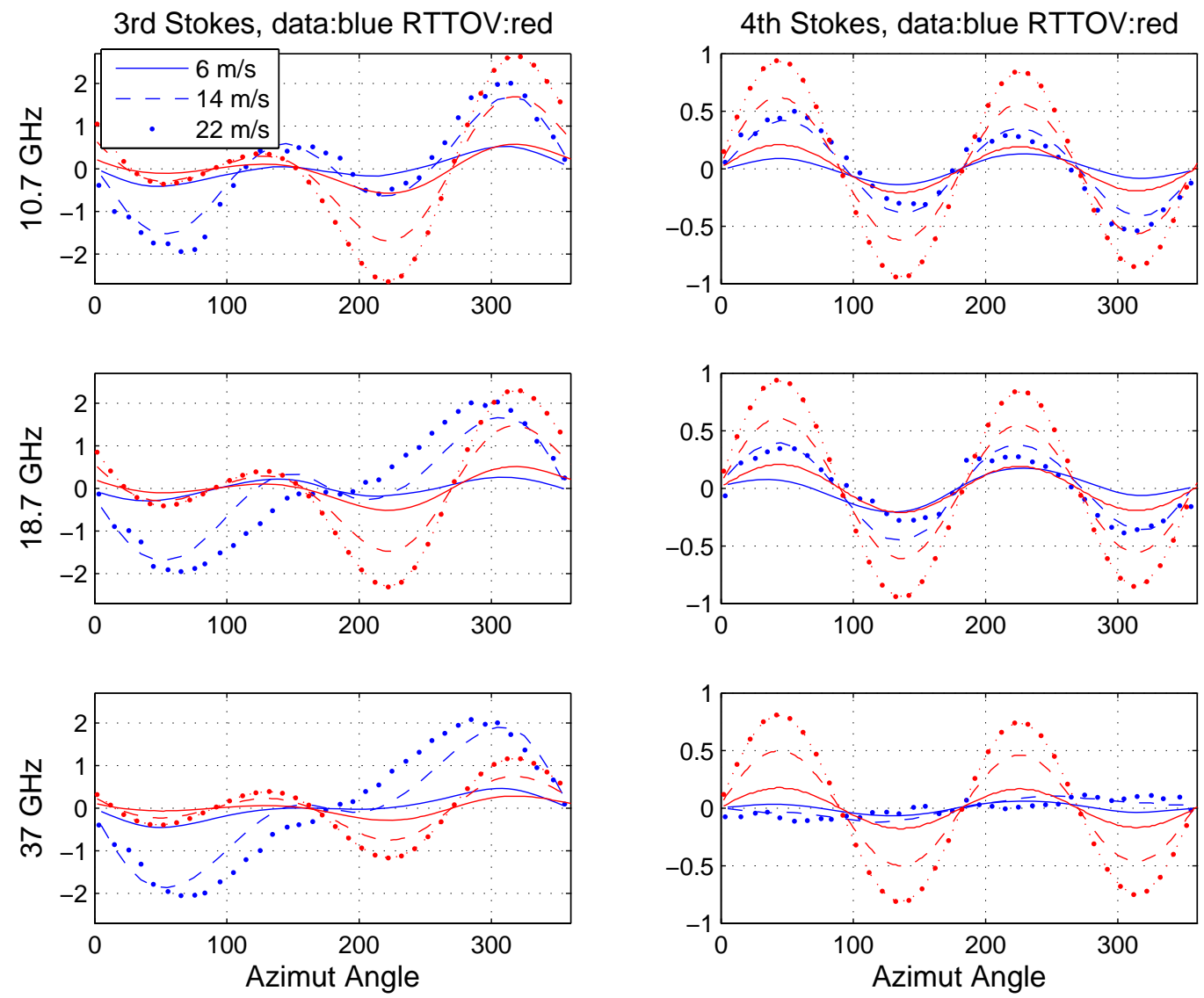

943

944 Figure 12: Mean 3rd (left panels) and 4th (right panels) Stokes parameters for WindSat 945 (blue lines) and RTTOV-8 model (red lines) binned as a function of the relative wind 946 direction (degrees), at $10.7 \mathrm{GHz}$ (top), $18.7 \mathrm{GHz}$ (middle), and $37.0 \mathrm{GHz}$ (bottom), and 947 for different wind speed ranges: $4 \mathrm{~m} / \mathrm{s}<\mathrm{WS}<8 \mathrm{~m} / \mathrm{s}$ (solid lines), $12 \mathrm{~m} / \mathrm{s}<\mathrm{WS}<16 \mathrm{~m} / \mathrm{s}$ 948 (dashed lines), $20 \mathrm{~m} / \mathrm{s}<\mathrm{WS}<24 \mathrm{~m} / \mathrm{s}$ (dotted lines). 

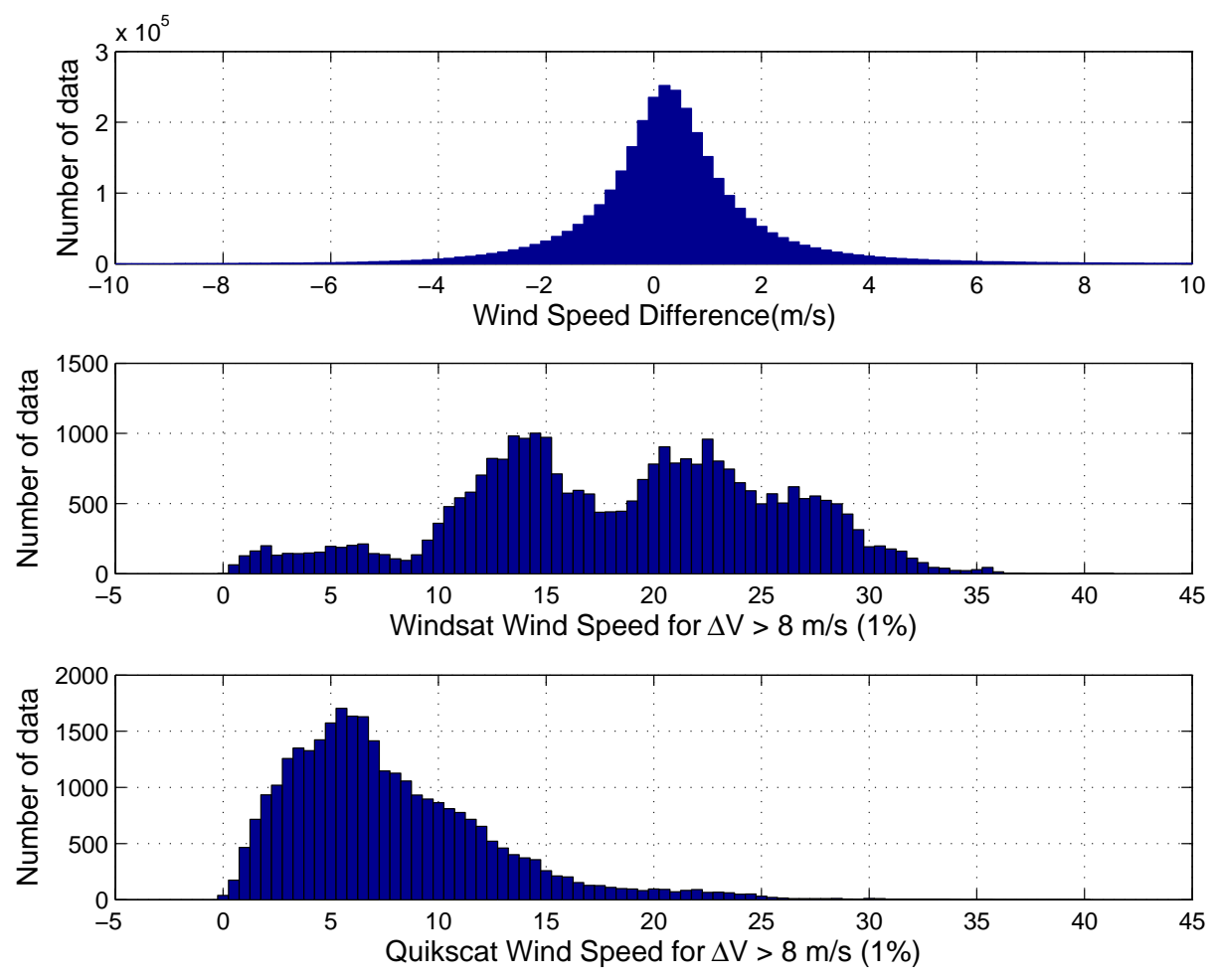

959 Figure 13: WindSat minus QuikSCAT wind speed difference distribution (top panel),

960 WindSat (middle panel) and QuikSCAT (bottom panel) wind speed distribution for wind

961 speed differences greater than $8 \mathrm{~m} / \mathrm{s}$. 


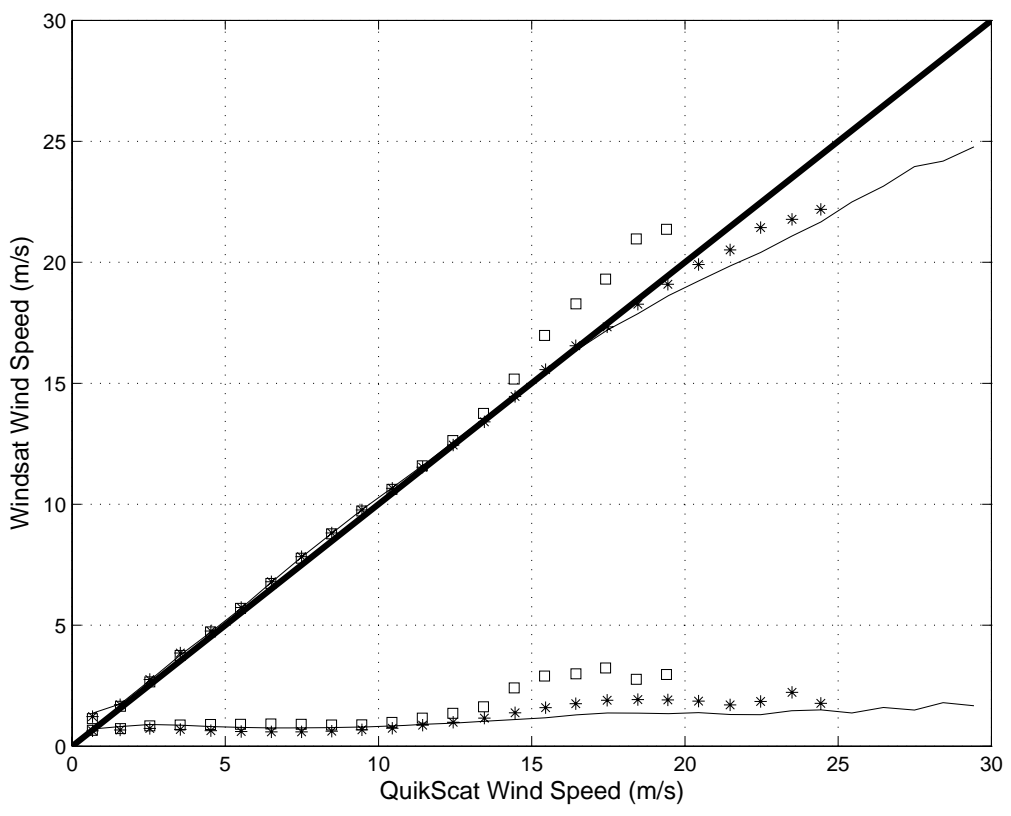

971 Figure 14: Mean WindSat speeds binned by QuikSCAT wind speeds, for $0 \mathrm{~mm}<\mathrm{WV}<$

$97220 \mathrm{~mm}$ (solid lines), $20 \mathrm{~mm}<\mathrm{WV}<40 \mathrm{~mm}$ (star), and $40 \mathrm{~mm}<\mathrm{WV}<80 \mathrm{~mm}$ (squares).

973 The thick solid line is the perfect fit line. The bottom curves display the standard

974 deviation of the WindSat minus QuikSCAT differences. WV stands for the WindSat 975 integrated water vapor content. Each bin contains at least 50 collocated measurements. 

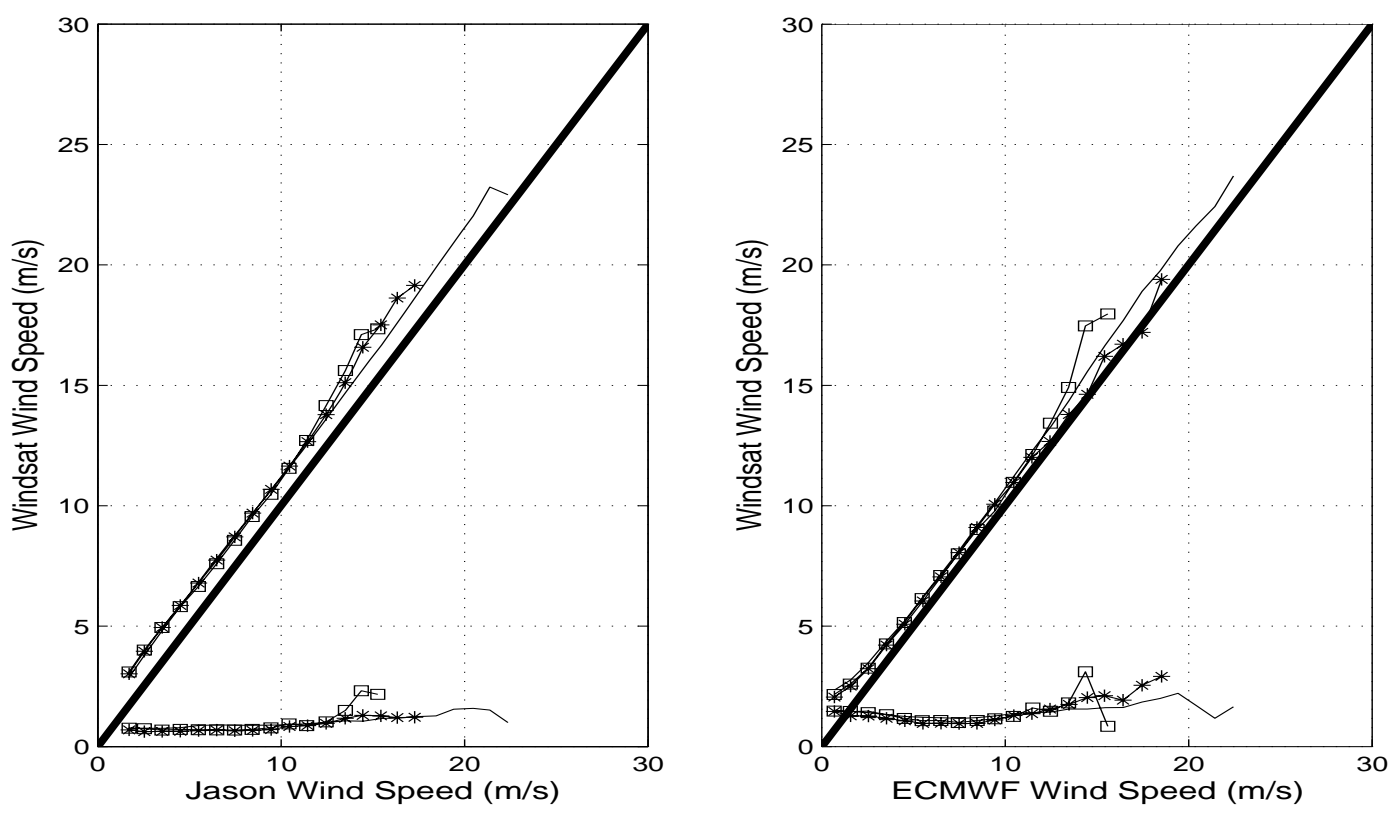

985

986 Figure 15: Mean WindSat speeds binned by Jason winds (left) and ECMWF winds

987 (right), for $0 \mathrm{~mm}<\mathrm{WV}<20 \mathrm{~mm}$ (solid lines), $20 \mathrm{~mm}<\mathrm{WV}<40 \mathrm{~mm}$ (star signs), and 40

$988 \mathrm{~mm}<\mathrm{WV}<80 \mathrm{~mm}$ (square signs). The thick solid line is the perfect fit line. The bottom

989 curves display the standard deviation of the WindSat minus Jason (left) and ECMWF

990 (right) differences. WV is retrieved from the Jason JMR radiometer. Each bin contains at

991 least 20 points. 

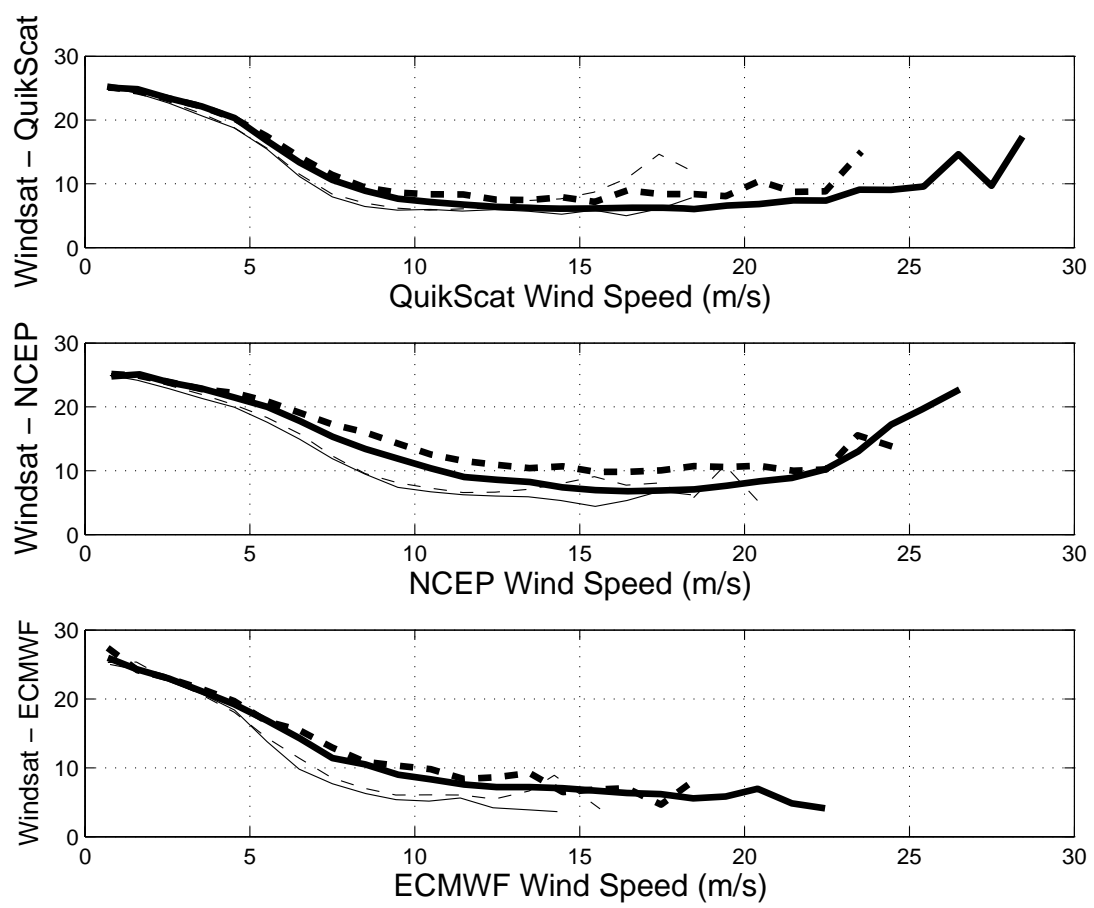

1001 Figure 16: Standard deviation (degrees) of the WindSat wind direction minus QuikSCAT

1002 (top panel), NCEP (middle panel), ECMWF (bottom panel) wind direction, as a function

1003 of wind speed in tropical (thin lines) and mid-latitude areas (thick lines). WV ranges are 0

$1004 \mathrm{~mm}<\mathrm{WV}<20 \mathrm{~mm}$ (solid lines) and $20 \mathrm{~mm}<\mathrm{WV}<80 \mathrm{~mm}$ (dashed lines). A minimum

1005 of 50 data points is required in each $1 \mathrm{~m} / \mathrm{s}$ bin. 

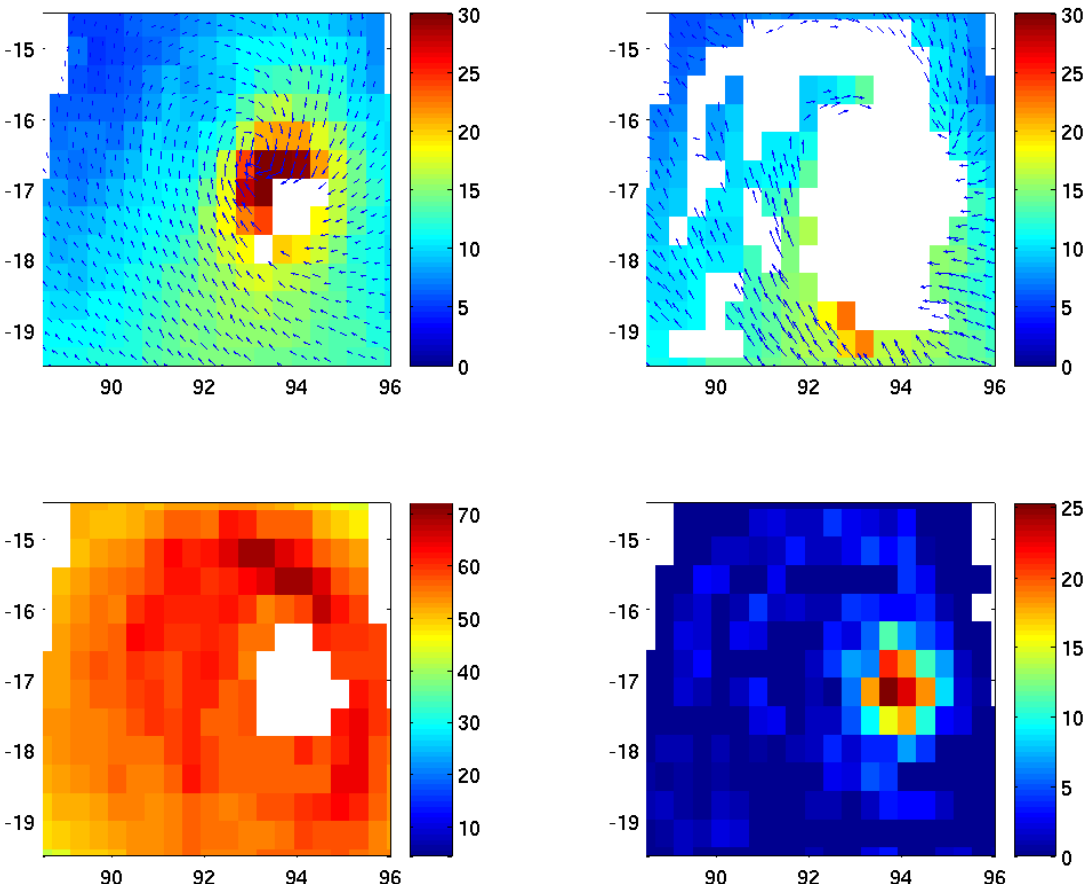

1014 Figure 17: QuikSCAT (top left) and WindSat (top right) wind fields, speed in $\mathrm{m} / \mathrm{s}$, for

1015 non rainy areas, in a tropical storm, February 10, 2003, 12h00 UTC. WindSat integrated

1016 water vapor content (bottom left in $\mathrm{mm}$ ) and rain rate (bottom right in $\mathrm{mm} / \mathrm{hr}$ ).

1017

1018 


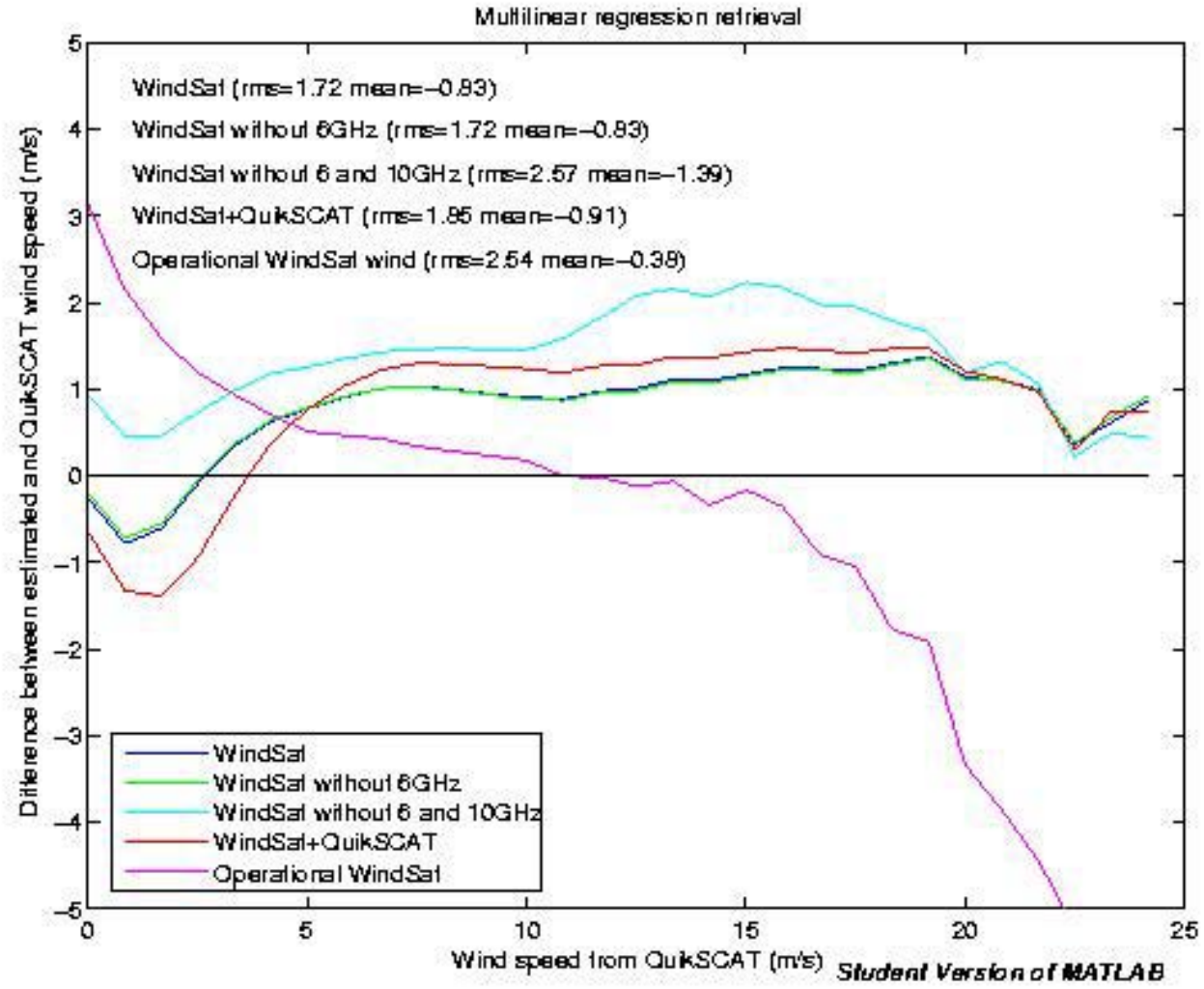

1024

1025 Figure 18: Wind speed errors for different combinations of observations, stratified by the

1026 QuikSCAT wind speed taken as a reference. For each combination, the rms and mean

1027 errors calculated over the original data set (including rainy pixels) are indicated. 